\title{
Upper-Ocean Response to Precipitation Forcing in an Ocean Model Hindcast of Hurricane Gonzalo
}

\author{
JOHN STEFFEN $^{\mathrm{a}}$ AND MARK BOURASSA ${ }^{\mathrm{b}}$ \\ ${ }^{\mathrm{a}}$ Department of Physical Oceanography, Woods Hole Oceanographic Institution, Woods Hole, Massachusetts; ${ }^{\mathrm{b}}$ Department of \\ Earth, Ocean and Atmospheric Science, Florida State University, Tallahassee, Florida
}

(Manuscript received 12 November 2019, in final form 27 August 2020)

\begin{abstract}
Preexisting, oceanic barrier layers have been shown to limit turbulent mixing and suppress mixed layer cooling during the forced stage of a tropical cyclone (TC). Furthermore, an understanding of barrier layer evolution during TC passage is mostly unexplored. High precipitation rates within TCs provide a large freshwater flux to the surface that alters upper-ocean stratification and can act as a potential mechanism to strengthen the barrier layer. Ocean glider observations from the Bermuda Institute of Ocean Sciences (BIOS) indicate that a strong barrier layer developed during the approach and passage of Hurricane Gonzalo (2014), primarily as a result of freshening within the upper $30 \mathrm{~m}$ of the ocean. Therefore, an ocean model case study of Hurricane Gonzalo has been designed to investigate how precipitation affects upper-ocean stratification and sea surface temperature (SST) cooling during TC passage. Ocean model hindcasts of Hurricane Gonzalo characterize the upper-ocean response to TC precipitation forcing. Three different vertical mixing parameterizations are tested to determine their sensitivity to precipitation forcing. For all turbulent mixing schemes, TC precipitation produces near-surface freshening of about $0.3 \mathrm{psu}$, which is consistent with previous studies and in situ ocean observations. The influence of precipitation-induced changes to the SST response is more complicated, but generally modifies SSTs by $\pm 0.3^{\circ} \mathrm{C}$. Precipitation forcing creates a dynamical coupling between upper-ocean stratification and current shear that is largely responsible for the heterogeneous response in modeled SSTs.
\end{abstract}

KEYWORDS: Air-sea interaction; Hurricanes/typhoons; Salinity; Ocean models

\section{Introduction}

The surface heat flux exchange from the ocean to the atmosphere is responsible for driving tropical cyclone (TC) development and intensification; therefore, air-sea interactions are fundamental to understanding TC intensity changes (Shay et al. 2000; Cione and Uhlhorn 2003). Ocean turbulent mixing, localized upwelling, and the entrainment of cooler thermocline water causes the ocean mixed layer (OML) and sea surface temperature (SST) to cool during TC passage (Fisher 1958; Leipper 1967; Elsberry et al. 1976; Price 1981). A negative feedback between upper-ocean cooling and TC intensity occurs due to a reduction in surface heat fluxes (Emanuel 1995; Xu and Wang 2010). Previous studies based on satellite observations (Grodsky et al. 2012; Reul et al. 2014), in situ measurements (Domingues et al. 2015; Rudzin et al. 2017, 2019) and ocean modeling (Neetu et al. 2012; Vissa et al. 2013; Androulidakis et al. 2016; Hernandez et al. 2016; Yan et al. 2017; Hlywiak and Nolan 2019) have shown that salinity-driven stratification within the isothermal layer (known as an oceanic barrier layer) can limit SST cooling, resulting in a more favorable ocean state for TCs (Wang et al. 2011; Balaguru et al. 2012).

The oceanic response to translating TCs, as observed by Argo floats, has shown that barrier layer development is prevalent (Liu et al. 2007; Park et al. 2011; Wang et al. 2016; Steffen and Bourassa 2018). There are two main reasons for increases in the barrier layer during and after TC passage: 1) deepening of the thermocline and/or 2) freshening of the upper

Corresponding author: John Steffen, jsteffen@whoi.edu ocean (Steffen and Bourassa 2018). Near-surface freshening can play a meaningful role in upper-ocean stratification, which influences the direction and magnitude of ocean currents and the amount of vertical entrainment into the mixed layer. These processes are consequential to the energy exchange from the ocean to the TC. While Argo float observations of TC-ocean interactions can quantify the changes to barrier layer characteristics, the physical mechanisms responsible for barrier layer development are speculative (Steffen and Bourassa 2018). We show that the surface freshwater flux from precipitation is consequential to the near-surface salinity budget, which can affect barrier layer evolution. Furthermore, salinity-driven changes to ocean stratification modulates the dynamic ocean response to TC passage, which can affect upper-ocean cooling near the storm.

Currently, temperature and salinity observations within the upper ocean of nearby TCs lack the spatial and temporal sampling required to determine the dominant physical mechanisms that lead to barrier layer development. Therefore, an ocean-atmosphere modeling system, like the Coupled Ocean Atmosphere Wave Sediment Transport (COAWST) model (Warner et al. 2010), is necessary to investigate these relationships. The following model runs implement the Regional Ocean Modeling System (ROMS, Shchepetkin and McWilliams 2005) within the COAWST framework. By performing a realistic model simulation of Hurricane Gonzalo, the relative contributions to the near-surface salinity and temperature budgets can be diagnosed. The sensitivity of different turbulent mixing parameterizations to the freshwater forcing from precipitation is investigated. The magnitude and spatial extent of freshening is examined, along with the salinity-driven changes to near-surface 
ocean current shear. These changes in current shear are expected to impact upper-ocean mixing and the temperature response to Hurricane Gonzalo's passage.

In section 2, there is a description of the meteorological history of Hurricane Gonzalo, along with a brief introduction to in situ ocean glider measurements obtained during Hurricane Gonzalo's passage. Then, an overview of the ROMS-only model setup and atmospheric fields used to force the model are discussed in sections 3 and 4, respectively. An analysis of Anna glider measurements of the upper response to Hurricane Gonzalo and a comparison to ROMS model experiments are provided in section 5. Detailed results on the modeled salinity and temperature responses, including budget analyses are presented in section 6 . In addition, the role of dynamical coupling between near-surface stratification and ocean current shear in determining the SST response is discussed.

\section{Hurricane Gonzalo case study}

Hurricane Gonzalo (2014) was selected for this case study for several reasons. First, ocean glider data from the Bermuda Institute of Ocean Sciences (BIOS) indicate that a strong barrier layer developed during Hurricane Gonzalo's passage (Curry and Guishard 2016). The barrier layer was established by a strong freshwater signal in the upper $30 \mathrm{~m}$ of the ocean and a deepening of the thermocline. Second, these targeted oceanic observational data are available for model verification of the upper-ocean response to Hurricane Gonzalo. Third, measurements obtained during Hurricane Gonzalo were well sampled in space and time, which produced highquality atmospheric observations to force the ROMS-only model simulation.

\section{Meteorological history}

The precursor disturbance to Hurricane Gonzalo exited the African coast on 4 October 2014 as a convectively active tropical wave (Brown 2015). The tropical disturbance struggled to develop due to strong westerly wind shear associated with an upper-level trough positioned over the central, tropical Atlantic Ocean. As the disturbance approached the Lesser Antilles, the National Hurricane Center classified the storm as a tropical depression at 0000 UTC 12 October. The system was named Tropical Storm Gonzalo just $12 \mathrm{~h}$ later, when it was located about $220 \mathrm{n} \mathrm{mi}(1 \mathrm{n} \mathrm{mi}=1.852 \mathrm{~km})$ east of Antigua. After a period of rapid intensification, Gonzalo attained hurricane status at 1200 UTC 13 October (Brown 2015). Hurricane Gonzalo continued on a northwestward track around the periphery of the North Atlantic subtropical high pressure zone for the next $36 \mathrm{~h}$ and rapidly intensified into a major hurricane by 1800 UTC 14 October. Peak intensity occurred around 1200 UTC 16 October, with a minimum surface pressure of $940 \mathrm{hPa}$ and 1-min sustained surface wind speeds of $125 \mathrm{kt}(1 \mathrm{kt}$ $\approx 0.51 \mathrm{~m} \mathrm{~s}^{-1}$ ). Due to increased southwesterly shear and cooler SSTs, Hurricane Gonzalo began to weaken as it approached Bermuda (Brown 2015). Strong tropical convection persisted, and the most intense precipitation rates were confined to the front quadrants. The wind shear vector was aligned with the storm translation direction during the 2-day period prior to landfall. In addition, trough interaction potentially added a baroclinic enhancement of the precipitation field in the front, left quadrant. Both of these elements lead to precipitationdriven freshening of the upper ocean ahead of the storm and facilitated barrier layer development. Hurricane Gonzalo made landfall on Bermuda just after 0000 UTC 18 October as a strong category 2 hurricane with surface winds of $95 \mathrm{kt}$ (Brown 2015).

\section{ROMS ocean model configuration}

The COAWST modeling system is composed of individual, open-source models designed to address coupled processes (Warner et al. 2010). The modeling system can be setup in a variety of ways, utilizing either coupled or uncoupled configurations. For this study, we performed ROMS-only model simulations of the upper-ocean response to the wind forcing from Hurricane Gonzalo using research-quality observations and reanalysis products as atmospheric forcing. All six ROMS model runs implement the same initial conditions and atmospheric forcing. The only differences between the experiments are the selection of the three vertical, turbulent mixing schemes and whether precipitation forcing is prescribed or not. For runs without precipitation forcing, the ROMS input forcing file simply sets the precipitation rate field to zero. The different experiments test the model sensitivity to precipitation forcing and how the additional freshwater flux influences the dynamic and thermodynamic responses of the upper ocean to Hurricane Gonzalo.

\section{a. ROMS-only model hindcasts}

The ROMS-only model hindcasts are performed for the 4-day period from 0000 UTC 15 October to 0000 UTC 19 October 2014. This period includes when Hurricane Gonzalo was undergoing rapid intensification to the north of Puerto Rico, captures the Bermuda landfall (0030 UTC 18 October), and concludes about a day later as Gonzalo was nearing extratropical transition. The initial conditions, boundary conditions, and climatology fields are derived from the HYCOM + NCODA Global 1/12 analysis (Chassignet et al. 2007; Cummings 2005). Atmospheric forcing fields supplied to ROMS include 2-m temperature, 2-m relative humidity, sea level pressure, $10-\mathrm{m}$ vector winds, precipitation rate, and radiative fluxes.

ROMS model output variables are computed every $30 \mathrm{~s}$ for the parent grid and every $15 \mathrm{~s}$ for the child grid. Averaged and diagnostic fields are output every hour of the model integration. The domain of the ROMS parent grid covers $15^{\circ}-40^{\circ} \mathrm{N}$ latitude and $55^{\circ}-75^{\circ} \mathrm{W}$ longitude, which includes a large portion of the tropical and subtropical Atlantic Ocean (Fig. 1). The outer grid spacing is $0.05^{\circ}$, or between 5 and $6 \mathrm{~km}$. The higher-resolution, nested grid is a $5^{\circ} \times 5^{\circ}$ box that covers the region from $28^{\circ}$ to $33^{\circ} \mathrm{N}$ latitude and from $62.5^{\circ}$ to $67.5^{\circ} \mathrm{W}$ longitude. The inner grid spacing is $0.0167^{\circ}$, or about $2 \mathrm{~km}$; it includes Bermuda and the area to the south where the Anna glider measured temperature and salinity profiles. A depiction of both grids, including high-resolution coastlines and ocean bathymetry are shown in Fig. 1 . The vertical grid has 40 layers, with approximately 13 vertical layers within the upper $150 \mathrm{~m}$ of the open ocean. 


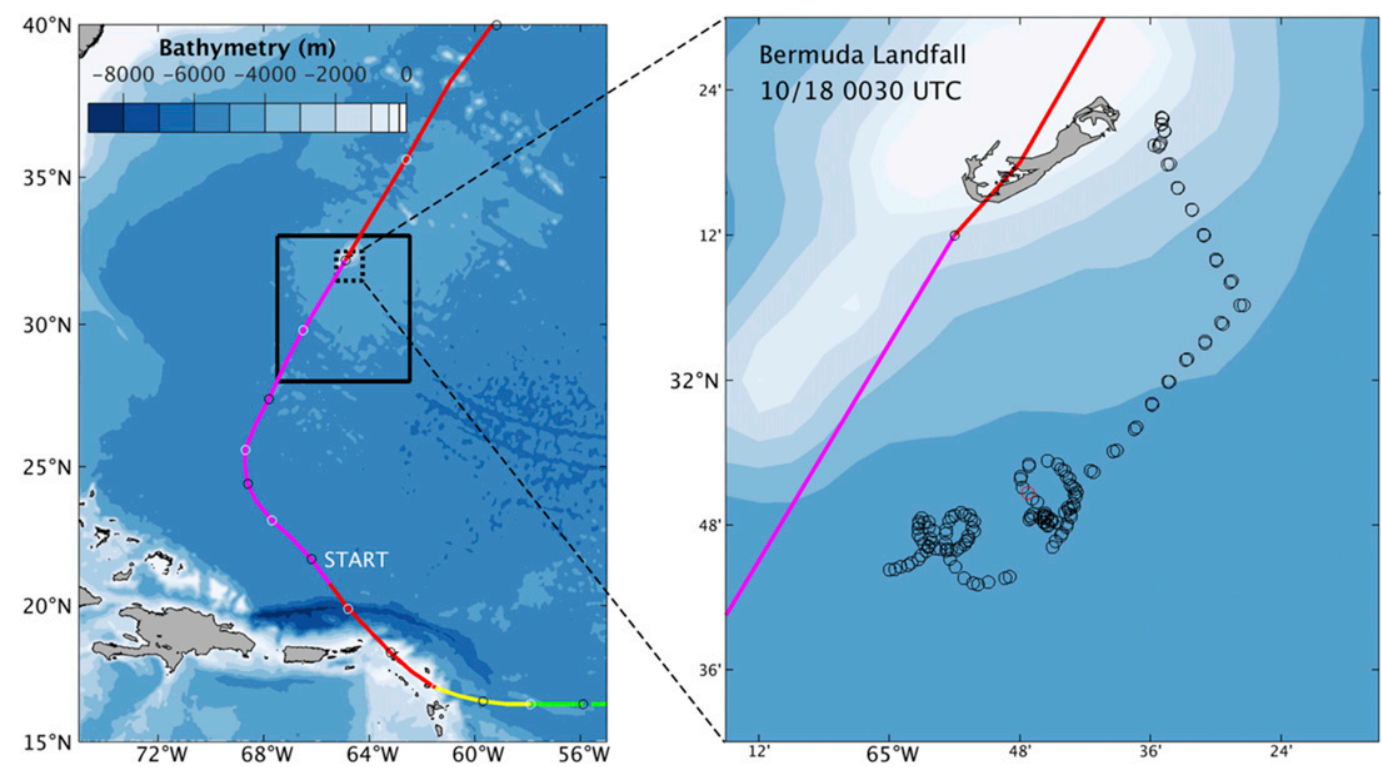

FIG. 1. (left) ROMS model domain with contoured bathymetry from ETOPO2. The HURDAT2 best track for Hurricane Gonzalo is plotted with intensity (tropical depression, green; tropical storm, yellow; hurricane, red; major hurricane, magenta). The nested ROMS domain is outlined in black. The dashed box indicates the area of Anna glider measurements, with (right) a close up view of Bermuda and Anna glider measurement locations.

\section{b. Vertical mixing parameterizations}

The three vertical turbulent mixing closure schemes tested in the ROMS-only hindcasts of Hurricane Gonzalo are the Large-McWilliams-Doney (LMD), Mellor-Yamada 2.5 (MY2.5), and generic length-scale (GLS) parameterizations (Warner et al. 2005). Each of these parameterizations is forced with and without precipitation to examine the salinity and temperature responses to Hurricane Gonzalo. In addition, we determine which terms in the upper-ocean salinity budget are sensitive to surface freshwater forcing and what the implications are for near-surface ocean currents and SSTs within the TC environment.

The LMD vertical mixing parameterization is a first-order scheme based on boundary layer similarity theory to establish a $K$-profile parameterization (Large et al. 1994). A particularly important feature of the LMD parameterization is the ability of the boundary layer to penetrate the thermocline and induce ocean mixed layer entrainment during strong wind-forcing events. For this reason, LMD is a logical selection for a vertical mixing parameterization under TC wind-forcing conditions. The MY2.5 turbulence closure parameterization is a synthesis of second-moment turbulent closure schemes (Mellor and Yamada 1982). MY2.5 is a widely utilized turbulence closure parameterization and it has been applied under TC wind forcing. The GLS parameterization implements a tunable set of length scale equations (Umlauf and Burchard 2003). The chosen parameters for this study are the generic version of the GLS turbulent mixing parameterization.

\section{Atmospheric forcing of ROMS}

To implement the most realistic ROMS ocean hindcasts of Hurricane Gonzalo, research-quality atmospheric and oceanic observations are used to force the model. Atmospheric surface variables of 2-m temperature, 2-m relative humidity, and sea level pressure are retrieved from the National Centers for Environmental Prediction (NCEP) Global Forecast System Final Analysis (GFS-FNL) ds083.2 dataset (NOAA/NCEP 2000). H*Wind surface winds are used as the surface momentum forcing (Powell et al. 1998, 2010). The Integrated Multisatellite Retrieval (IMERG) product from the Global Precipitation Measurement (GPM) mission is used for precipitation rates (Huffman et al. 2018). Surface fluxes of both longwave and shortwave radiation are retrieved from the hourly product of the Clouds and the Earth's Radiant Energy System (CERES; Wielicki et al. 1996; Doelling 2017). A more detailed description of the atmospheric forcing variables is provided in Table 1 . All of these variables have different grid spacing and temporal resolution. Therefore, the forcing input variables were all interpolated to the ROMS parent grid using a cubic spline interpolation method. Furthermore, a time interpolation was applied to input data with coarser temporal sampling to produce 3-hourly fields, starting from 0000 UTC 15 October and ending on 0000 UTC 19 October.

\section{a. $H^{*}$ Wind surface wind forcing}

$\mathrm{H}^{*}$ Wind surface wind analyses of hurricanes are qualitycontrolled, observation-based data products that are produced in near-real time and for historical TCs (Powell et al. 1998). $\mathrm{H}^{*}$ wind products have a long history of research-based use, including model validation and use as surface wind forcing for ocean, wave, and coastal storm surge models. For this study, $\mathrm{H}^{*}$ Wind fields provide the mechanical surface forcing to ROMS. Surface winds are rescaled from 1-min maximum 
TABLE 1. Sources for atmospheric forcing variables used in the ROMS-only hindcasts of Hurricane Gonzalo along with horizontal grid spacing and temporal resolution information.

\begin{tabular}{|c|c|c|c|}
\hline Source & Variables (units) & $\begin{array}{l}\text { Horizontal grid } \\
\text { spacing }\end{array}$ & $\begin{array}{l}\text { Temporal } \\
\text { resolution }\end{array}$ \\
\hline NCEP Final Analysis (GFS-FNL) ds083.2 & $\begin{array}{l}\text { 2-m air temperature }\left({ }^{\circ} \mathrm{C}\right), 2-\mathrm{m} \text { relative humidity }(\%) \text {, mean sea } \\
\text { level pressure }(\mathrm{hPa})\end{array}$ & $1^{\circ} \times 1^{\circ}$ & $6 \mathrm{~h}$ \\
\hline $\mathrm{H} *$ Wind surface wind analysis & $10-\mathrm{m}$ wind speed $\left(\mathrm{m} \mathrm{s}^{-1}\right)$ & $\sim 1 \mathrm{~km}$ & $3 \mathrm{~h}$ \\
\hline GPM IMERG & Precipitation rate $\left(\mathrm{kg} \mathrm{m}^{-2} \mathrm{~s}^{-1}\right)$ & $0.1^{\circ} \times 0.1^{\circ}$ & $30 \mathrm{~min}$ \\
\hline CERES radiation & $\begin{array}{l}\text { Longwave }\left(\mathrm{W} \mathrm{m}^{-2}\right) \text {, longwave down }\left(\mathrm{W} \mathrm{m}^{-2}\right) \text {, } \\
\text { shortwave }\left(\mathrm{W} \mathrm{m}^{-2}\right)\end{array}$ & $0.25^{\circ} \times 0.25^{\circ}$ & $1 \mathrm{~h}$ \\
\hline
\end{tabular}

winds to a 10-min average using a conversion factor of 0.93 that is recommended by the World Meteorological Organization for TC conditions (Harper et al. 2010). The maximum $\mathrm{H}^{*}$ Wind surface wind speed footprint during the ROMS model integration is shown in Fig. 2a.

$\mathrm{H}^{*}$ Wind analyses are storm-centered and can vary in domain size depending on the spatial area of gale force winds. When the $\mathrm{H}^{*}$ Wind fields are interpolated to the ROMS domain, there are peripheral areas without any wind forcing data. Therefore, the GFS winds are used to backfill the outer portions of the ROMS parent grid where $\mathrm{H}^{*}$ Wind data are absent. A linear mask is applied along the edges of the $\mathrm{H}^{*}$ Wind analysis to blend with the GFS winds. Near Hurricane Gonzalo, the wind forcing is entirely from the $\mathrm{H}^{*}$ Wind analysis. Outside of the $\mathrm{H}^{*}$ wind product domain, the wind forcing is entirely from the GFS FNL analysis.

\section{b. GPM IMERG precipitation rate}

The IMERG precipitation product of GPM synthesizes passive microwave retrievals from the GPM satellite constellation into a gridded, global Level 3 product with $0.1^{\circ} \times 0.1^{\circ}$ precipitation fields at half-hourly intervals (Huffman et al. 2018). Due to the transient nature of TCs, polar-orbiting satellite constellations often provide incomplete spatial coverage of the storm environment. In between periods with full spatial coverage of Hurricane Gonzalo, the precipitation rates are linearly interpolated in time and space to fill gaps in coverage using a storm-centered, $5^{\circ} \times 5^{\circ}$ box domain. The longest temporal gap in interpolated IMERG fields is $8 \mathrm{~h}$, with an average time gap of $3 \mathrm{~h}$.

The improved representation of TC precipitation produces a swath of storm-total precipitation that exceeds $300 \mathrm{~mm}$ along Hurricane Gonzalo's best track (Fig. 2b). Furthermore, individual snapshots of the IMERG precipitation rates with sufficient coverage of Hurricane Gonzalo often show a northern displacement of maximum precipitation rates. This northern displacement of maximum precipitation rates ahead of Hurricane Gonzalo, especially as the storm approached Bermuda, is responsible for the surface freshwater fluxes that promoted barrier layer development observed in the Anna
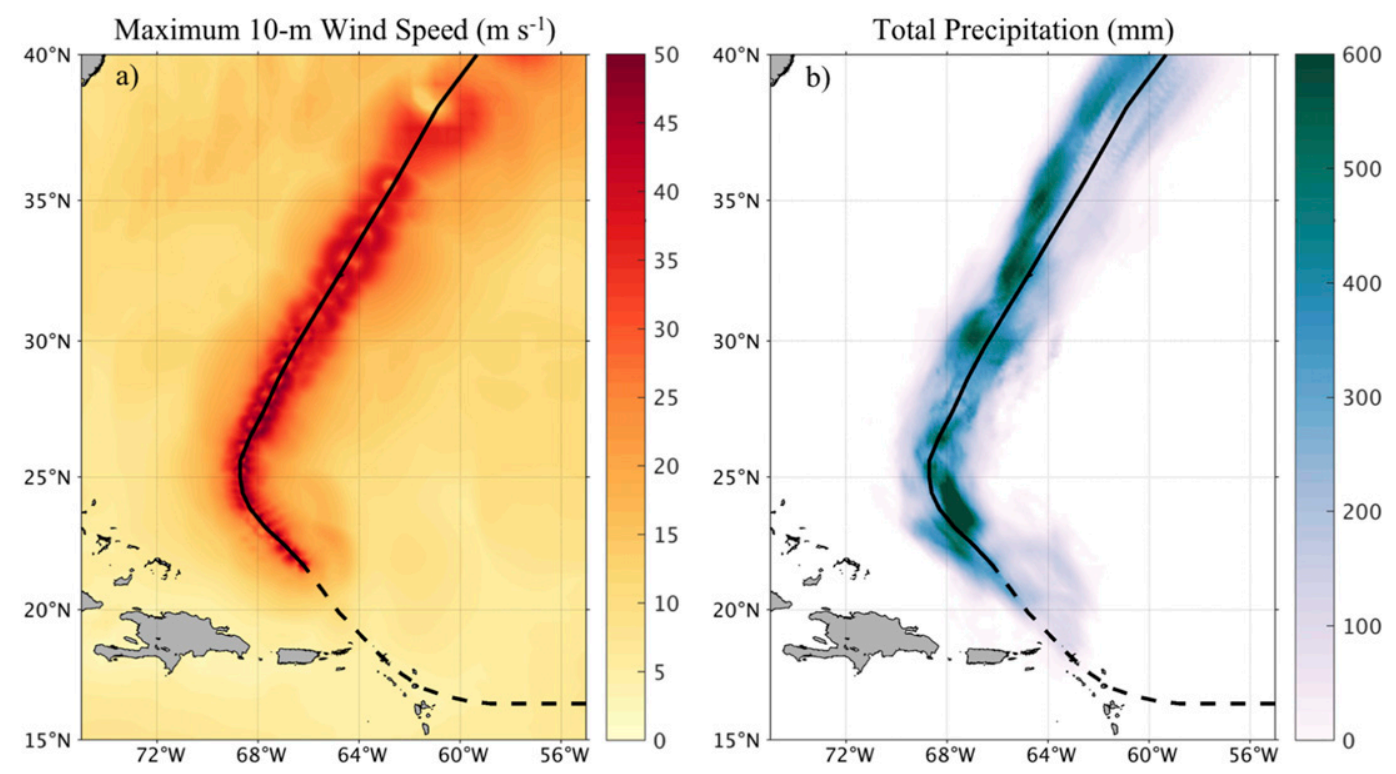

FIG. 2. Atmospheric forcing fields of (a) maximum 10-m wind speed and (b) total precipitation during 15-19 Oct 2014 with Hurricane Gonzalo best track plotted in black (dashed line indicates storm track before model run initiation). 

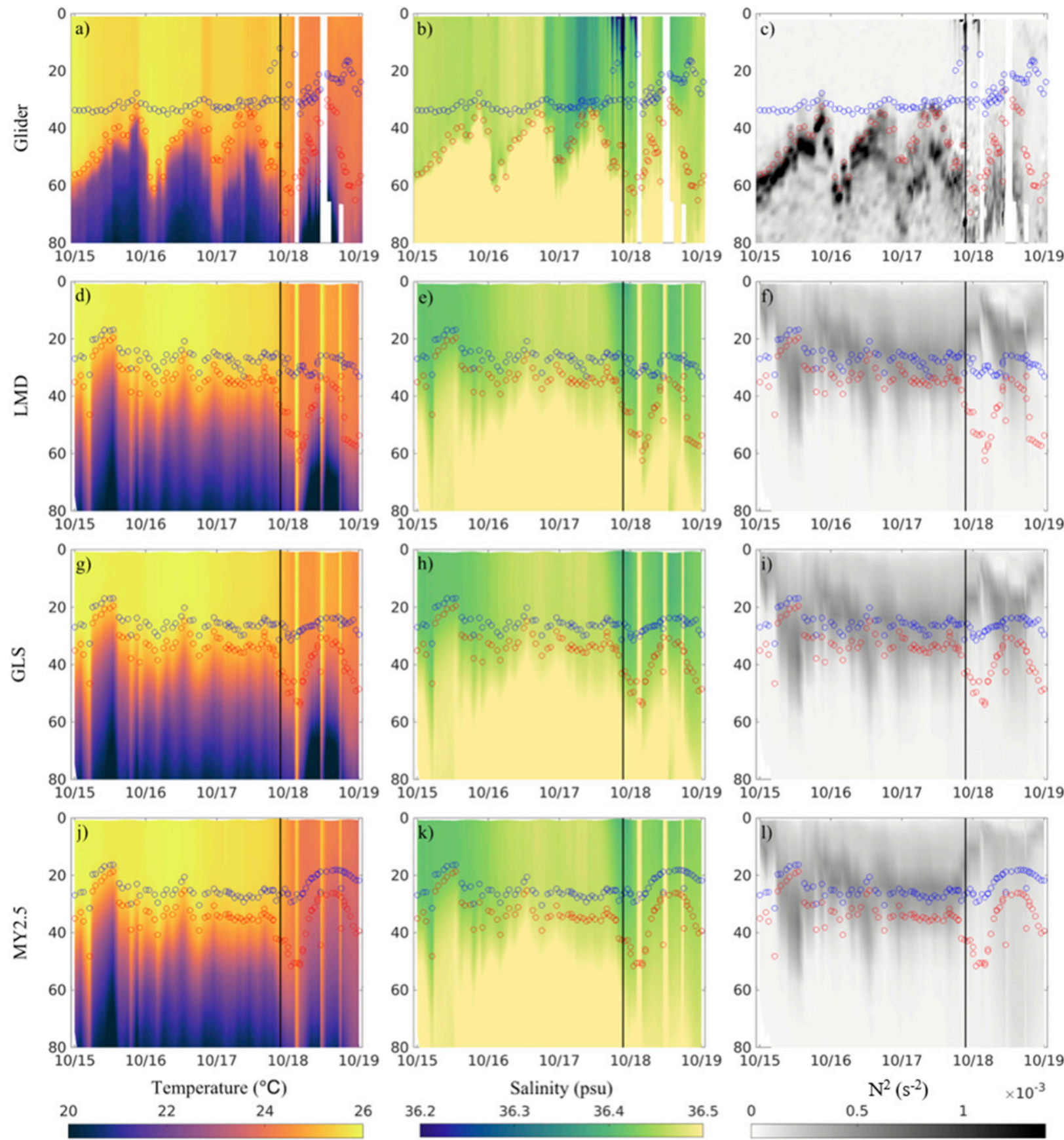

FIG. 3. Time-depth contour plots of (a) ocean temperature, (b) salinity, and (c) squared Brunt-Väisälä buoyancy frequency from Anna Slocum glider measurements during 15-19 Oct 2014. Measurements have vertical grid spacing of $1 \mathrm{~m}$, with the $y$ axis showing depths from the surface down to $80 \mathrm{~m}$. Discrete values of the pycnocline (blue) and thermocline (red) depths are plotted for each individual glider profile. The time of Hurricane Gonzalo's closest approach to the Anna glider is plotted (vertical black line). Collocated time-depth contour plots are shown for ROMS model output using different vertical, turbulent mixing schemes: (d)-(f) LMD, (g)-(i) GLS, and (j)-(1) MY2.5.

glider data (Figs. 3a-c and further explained in section 5). The TC precipitation field derived from IMERG data is used to force the ROMS model and to test the sensitivity of the different mixing parameterizations to the surface freshwater flux.

\section{Model comparison to glider observations}

A Slocum glider ("Anna") from the BIOS was deployed to sample the prestorm ocean state and cold wake response from Hurricane Fay (2014). The glider continued to make measurements during the passage of Hurricane Gonzalo, six days 
later (Curry and Guishard 2016). Anna was positioned to the right side of Hurricane Gonzalo's track, thus the glider sampled the upper ocean during Hurricane Gonzalo's approach and passage. Anna sampled the eyewall region beginning around 2100 UTC 17 October. As Hurricane Gonzalo's eyewall passed, the glider's rudder was sheared off, causing the instrument to function as a profiling, Lagrangian drifter for the remaining time. In total, Anna measured 152 upper-ocean profiles of temperature and salinity during the passage of Hurricane Gonzalo (Figs. 3a-c). The postprocessed vertical spacing of the glider data is $1 \mathrm{~m}$.

\section{a. Anna glider measurements}

Remnant internal waves along the thermocline are evident from the prior passage of Hurricane Fay. Also, the upper ocean was well mixed with ocean temperature near $26^{\circ} \mathrm{C}$, salinity near $36.4 \mathrm{psu}$ and minimal stratification within the upper $40 \mathrm{~m}$ of the ocean (Figs. 3a-c). Strong upper-ocean currents during the forced stage of Gonzalo resulted in large vertical shears within the mixed layer and the excitation of the internal waves along the thermocline. Thermocline displacements of nearly $50 \mathrm{~m}$ occurred with a near-inertial period of $\sim 23 \mathrm{~h}$ (Curry and Guishard 2016). The Anna glider measurements made during Hurricane Gonzalo's passage show a strong freshwater signal within the upper 30-40 $\mathrm{m}$ of the ocean (Fig. 3b). The decrease in salinity began a day before TC passage, as atmospheric vertical shear caused intense precipitation ahead of the storm track. The mixed layer response to Hurricane Gonzalo shows turbulent mixing extending beyond the thermocline depth and a reduction in mixed layer temperature by $\sim 2^{\circ} \mathrm{C}$ (Fig. 3a). Furthermore, stratification along the thermocline was very pronounced, with values of squared Brunt-Väisälä frequency as high as $1.4 \times 10^{-3} \mathrm{~s}^{-2}$. Below the thermocline, stratification was slightly lower, ranging from 0.25 to $0.75 \times 10^{-3} \mathrm{~s}^{-2}$. The 152 vertical profiles of temperature and salinity are used to validate ROMS model output. The following gridpoint analyses throughout section 5 use ROMS model grid points that are collocated in space and time to the Anna glider profiles, including the period when the glider acted as a profiling drifter.

\section{b. Collocated ROMS model response}

The ROMS temperature response throughout the upper $80 \mathrm{~m}$ of the ocean is mostly consistent with the Anna glider observations. Slight differences are present, however, such as the ROMS model having a slightly warmer mixed layer $\left(+0.2^{\circ} \mathrm{C}\right.$ bias $)$ and less coherent internal waves along the thermocline. Both of these features are likely related, since both are indicative of reduced mixing and entrainment at the thermocline depth. Furthermore, the pycnocline and thermocline tend to be shallower in the ROMS model runs (Fig. 3).

The largest differences between ROMS model output and the glider measurements is in the representation of upperocean salinity and stratification. The ROMS model shows a saltier upper ocean as Hurricane Gonzalo approaches and no appreciable surface freshening until right before TC passage. The ROMS model salinity response is delayed and of a smaller magnitude than the upper-ocean freshening measured by the Anna glider. This can result from an underrepresentation of the surface freshwater flux from precipitation in the ROMS model, since the IMERG precipitation product was shown to have limited sampling. Despite these upper-ocean salinity differences, the precipitation forcing applied to the ROMS model does produce upper-ocean freshening of $0.1-0.2 \mathrm{psu}$ during Hurricane Gonzalo's passage. The muted salinity response in the ROMS model likely sets a lower bound on salinity-driven impacts to barrier layer evolution and the mixed layer temperature response to Hurricane Gonzalo.

The stratification profile measured by the Anna glider shows a homogeneous mixed layer down to $30-40 \mathrm{~m}$ and a highly stratified 5-10-m-thick layer below that, along the thermocline (Fig. 3c). In effect, the wind stress forcing from Hurricane Gonzalo is more easily mix downward to the base of the mixed layer and can begin eroding the stratification maxima along the thermocline. During the forced stage of Hurricane Gonzalo, mixing certainly penetrates the thermocline as the stratification at the thermocline depth is reduced, as seen in the glider measurements. However, the representation of upper-ocean stratification from the ROMS model is strikingly different. First, the mixed layer has stronger stratification $\left(0.25-0.50 \times 10^{-3} \mathrm{~s}^{-2}\right)$ from the surface down to $30 \mathrm{~m}$ when compared to observations, which are near neutral (Fig. 3, right column). Second, the highly stratified layer at the base of the mixed layer is present in the ROMS model, but the layer is thicker and less stratified compared to the glider observations. Therefore, the ROMS model representation of turbulent mixing during Hurricane Gonzalo is likely to encounter more resistance throughout the upper ocean, but less resistance at the thermocline depth. While the prestorm stratification is very similar among the three turbulent mixing schemes, the MY2.5 scheme supports more mixing and mixed layer cooling. After Hurricane Gonzalo's passage, the stratification profile in MY2.5 (Fig. 31) is reduced when compared to LMD (Fig. 3f) and GLS (Fig. 3i).

\section{c. Response to precipitation forcing}

Differences in the upper-ocean response of the ROMS model to precipitation forcing during Hurricane Gonzalo are shown in Fig. 4. Positive (negative) values for salinity differences indicate where the ROMS model run with precipitation forcing is saltier (fresher) that the ROMS model run without precipitation forcing. Likewise, positive (negative) values for temperature differences indicate where the ROMS model runs with precipitation forcing are warmer (colder). Also, positive (negative) differences in $N^{2}$ show where precipitation acts to stabilize (destabilize) the upper ocean. The time-depth contour plots are collocated with glider observations (as in Fig. 3), but only show differences in ROMS model runs due to precipitation forcing. The three days leading up to Hurricane Gonzalo's passage are mostly unchanged among ROMS model runs, especially when using the LMD turbulent mixing scheme (Figs. $4 \mathrm{a}-\mathrm{c}$ ). There are minor differences in subthermocline temperatures in GLS (Fig. 4d) and MY2.5 (Fig. 4g) that develop around 0000 UTC 16 October, which likely result from random changes to internal wave properties along the thermocline. The upper-ocean temperature difference during and after Hurricane Gonzalo vary among the three turbulent 

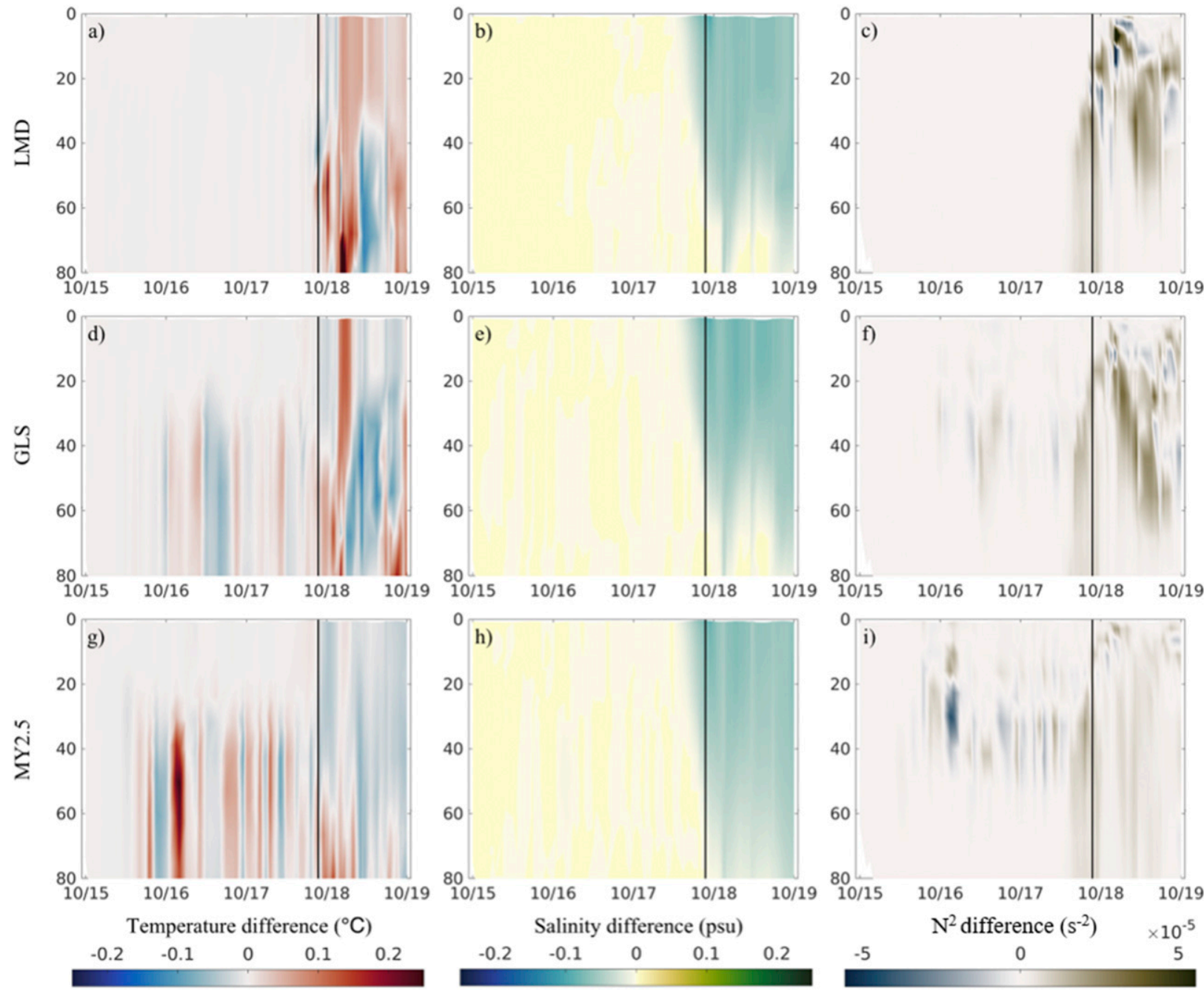

FIG. 4. Collocated time-depth contour plots of differences in (left) ocean temperature, (center) salinity, and (right) squared BruntVäisälä buoyancy frequency due to precipitation forcing during 15-19 Oct 2014. Model runs are performed using three different vertical, turbulent mixing schemes: (a)-(c) LMD, (d)-(f) GLS, and (g),(h) MY2.5. The time of Hurricane Gonzalo's closest approach to the Anna glider is plotted (vertical black line).

mixing schemes. LMD (with precipitation forcing) has stronger mixed layer cooling for several hours after TC passage, but is followed by a reduction in mixed layer cooling during the following day (Fig. 4a). Reduced mixed layer cooling for the LMD precipitation run is consistent with the hypothesis that the freshwater flux from precipitation can increase upper-ocean stability and limit entrainment. However, the MY2.5 with precipitation forcing has consistently stronger upper-ocean cooling when compared to the MY2.5 run without precipitation forcing (Fig. 4g). Therefore, the temperature responses to $\mathrm{TC}$ precipitation forcing is highly variable among the different turbulent mixing schemes. The salinity response among the three turbulent mixing schemes is more consistent, with upper-ocean freshening of 0.1-0.2 psu attributable to precipitation (Fig. 4, middle column). For LMD and GLS, the freshwater signal is mixed down to a depth of $\sim 60 \mathrm{~m}$, while MY2.5 has stronger and deeper mixing down to $\sim 80 \mathrm{~m}$. The differences in squared Brunt-Väisälä frequency due to precipitation show that the upper ocean is generally more stable in the ROMS model runs. Interestingly, the largest increases in stability occur at depth, and therefore the effects of precipitation forcing are not strictly confined to a near-surface layer (Fig. 4, right column). This is especially true for the LMD and GLS schemes where the stability increases are either propagated or mixed downward after Hurricane Gonzalo's passage.

\section{d. Barrier layer evolution}

Temperature and salinity profiles from the Anna glider show that barrier layer metrics began to increase the day before Hurricane Gonzalo made landfall on Bermuda. To remove the high frequency variations in barrier layer characteristics due to near-inertial oscillations, the glider-derived data was smoothed with a 24-h running mean (Fig. 5). The barrier layer thickness (BLT) recorded by Anna increased as Hurricane Gonzalo 

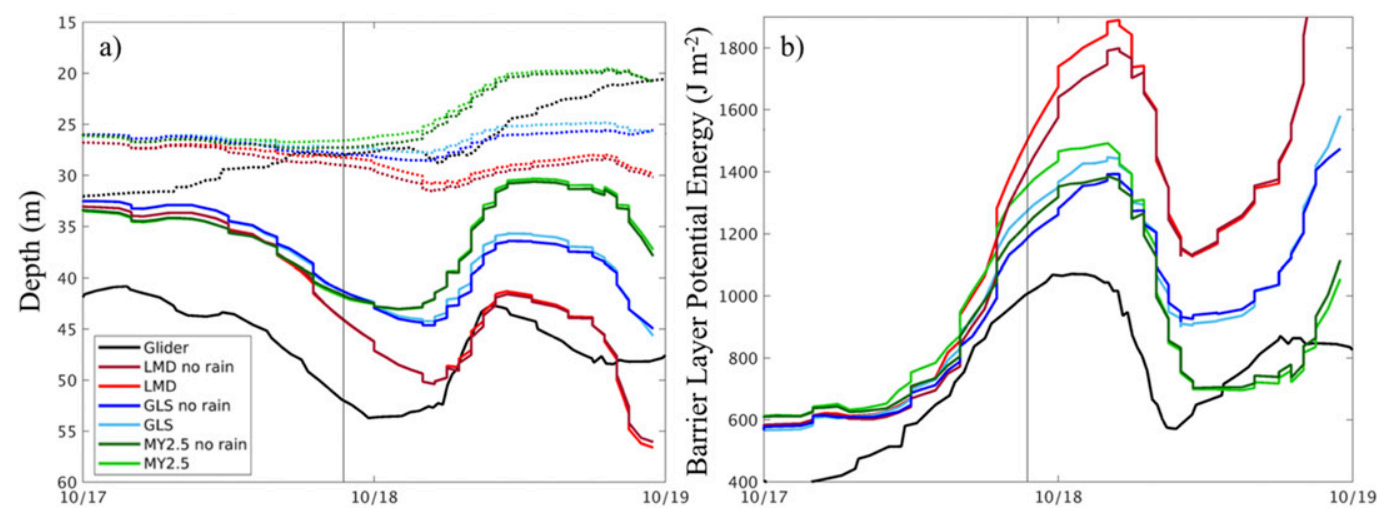

FIG. 5. (a) Time series of pycnocline (dashed) and thermocline (solid) depths from Anna glider measurements (black) compared to all six ROMS model runs during 17-19 Oct 2014. (b) As in (a), but for barrier layer potential energy.

approached and peaked at $23.5 \mathrm{~m}$ shortly after passage. The barrier layer thickness expanded as the thermocline deepened more than the pycnocline during TC passage (Fig. 5a). Likewise, the barrier layer potential energy (BLPE) increased to $\sim 1000 \mathrm{~J} \mathrm{~m}^{-2}$ at the time of TC passage, an increase of $150 \%$ from the prestorm observation $\left(\sim 400 \mathrm{~J} \mathrm{~m}^{-2}\right)$ recorded on 0000 UTC 17 October (Fig. 5b). However, less than a day after passage, both the pycnocline and thermocline began to shoal. The pycnocline depth decreased by $\sim 5 \mathrm{~m}$ and the thermocline depth decreased by $\sim 10 \mathrm{~m}$, resulting in a reduction in barrier layer thickness. By the end of the Anna observation period, BLPE had fallen to $\sim 300 \mathrm{~J} \mathrm{~m}^{-2}$, more than a $100 \mathrm{~J} \mathrm{~m}^{-2}$ decrease from the prestorm value. Continued turbulent mixing caused by inertial currents within Hurricane Gonzalo's cold wake quickly eroded the barrier layer.

The ROMS model runs have consistently shallower pycnocline and thermocline depths when compared to the glider observations (Fig. 5a). The modeled BLT is also thinner, with a difference of $\sim 10 \mathrm{~m}$ at the time of Hurricane Gonzalo's closest approach to the Anna glider. Both of these ROMS model properties should result in more mixed layer cooling in response to Hurricane Gonzalo. As an example, MY2.5 has the shallowest thermocline depth, and unsurprisingly has the most mixed layer cooling in response to Hurricane Gonzalo (Fig. 3j). Leading up to Hurricane Gonzalo's passage, the different turbulent mixing schemes have a consistent representation of pycnocline and thermocline depths, varying by less than $5 \mathrm{~m}$. Furthermore, ROMS model runs with precipitation forcing result in shoaling of the pycnocline by $1-2 \mathrm{~m}$, with minimal changes to the thermocline depths. Despite the shallower representation of the thermocline within the ROMS model, BLPE values are substantially higher than the glider observations (Fig. 5b). The larger BLPE values are a direct consequence of the ROMS model depicting stronger upper-ocean stratification above the thermocline. The LMD scheme produces BLPE values about $50 \%$ greater than the glider observations at the time of Hurricane Gonzalo's passage. Furthermore, all the precipitation runs have more BLPE compared to their no-precipitation run counterparts. The salinity-driven changes in stratification are manifested in larger BLPE values (Fig. 5b).

The SST response to Hurricane Gonzalo as observed by the Anna glider had a maximum near-surface ( $\sim 1$-m depth) cooling of $\sim 1.6^{\circ} \mathrm{C}$ which was accurately reproduced by the ROMS model (Fig. 6). Initially, there is a small positive bias in ROMS SSTs of $+0.2^{\circ} \mathrm{C}$ compared to the glider, but the ROMS model hindcasts do an excellent job of capturing SST cooling during Hurricane Gonzalo's passage. The LMD mixing scheme performed the best when compared to the glider observations, and spread among the three turbulent mixing schemes was $\sim 0.5^{\circ} \mathrm{C}$. The MY2.5 produced the most cooling and is nearly a half degree cooler than the LMD and GLS SSTs at 0600 UTC 18 October (Fig. 6).

The increase in thermocline depth and the freshening within the upper $\sim 30 \mathrm{~m}$, as observed by the Anna glider, resulted in barrier layer development during Hurricane Gonzalo. These changes are consistent with the upper quartile results from the TC-Argo float dataset presented in Steffen and Bourassa 2018. Due to the higher sampling frequency of Anna (1-2h) compared to most Argo float observations (10 days), the freshwater lens generated by Hurricane Gonzalo is captured before advective and mixing processes begin to obscure the freshwater signal. These glider observations provide a rare glimpse into the ocean state response near the center of a TC and they are critical for validating the upper-ocean response in the ROMS model runs.

\section{ROMS ocean surface response}

The ROMS model salinity response to TC precipitation forcing (Fig. 7) is consistent with previous literature (Jacob and Koblinsky 2007; Jourdain et al. 2013; Steffen and Bourassa 2018), namely that there is a near-surface freshening of 0.3 psu during TC passage. This surface freshwater anomaly is typically eroded over several days due to continued turbulent mixing from near-inertial ocean currents in Hurricane Gonzalo's cold wake. The SST response is more heterogeneous, with both areas of warming and cooling in response to precipitation forcing. This section will discuss the dominant terms in both the surface salinity and temperature 


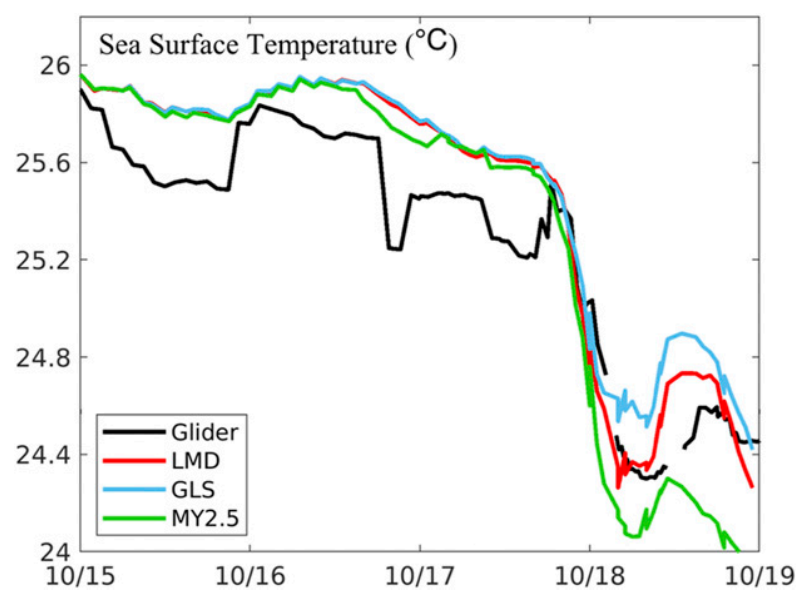

FIG. 6. Time series of SST ( 1-m depth) measured by the Anna glider compared to ROMS model SSTs (with precipitation forcing) using different vertical, turbulent mixing schemes: LMD (red), GLS (blue), and MY2.5 (green).

budgets under TC conditions. Finally, the physical mechanisms that lead to the model results are discussed.

\section{a. ROMS tendency terms}

The ROMS model performs online calculations of the salinity and temperature tendencies in its diagnostic output. The tendency equations have four main terms that determine the total rate of change: horizontal advection (HADV), horizontal diffusion (HDIF), vertical advection (VADV), and vertical diffusion (VDIF). The surface forcing term is not a separate term in the tendency budget, but it does affect the advection and diffusion terms. For the advection terms, Ekman dynamics are included. For the vertical diffusion term, entrainment and turbulent mixing are included. Of these terms, the horizontal diffusion is several orders of magnitude smaller than the others, and therefore, it is negligible. Both the vertical advection and horizontal advection terms are an order of magnitude larger $\left(10^{-5}\right)$ than the vertical diffusion $\left(10^{-6}\right)$ term. However, the vertical and horizontal advection terms mostly cancel out. The cancellation between the vertical and horizontal advection terms within the tendency budgets is a consequence of the continuity equation. Any upward motion and transport are balanced by a nearly equal and opposite horizontal transport at the surface. The residual total advection (TADV) term highlights areas where there is not a perfect cancellation between the VADV and HADV terms. In areas with strong vertical gradients in either SSS or SST (i.e., near the surface of the thermocline), vertical advection will make a larger contribution to the tendency budgets through the TADV term. Both the TADV and VDIF terms become important when determining the precipitation-driven changes to the tendency budgets.

The ROMS model tendency differences are collected over a $250-\mathrm{km}$ radius that is centered on Hurricane Gonzalo. The tendencies are collected at all hourly time steps and averaged over the first 2.5 days of ROMS model runs, from 0030 UTC 15 October through 1230 UTC 17 October. Radial contour plots show the storm-relative structure of the tendencies, as well as their individual components. Boxplots of tendencies are used to determine the median values and 25 th and 75 th quartiles of the tendency rates and primary terms within the budget.

\section{b. Salinity response}

The sea surface salinity (SSS) response to the precipitation forcing from Hurricane Gonzalo results in surface freshening across all three mixing parameterizations (Fig. 7). The magnitude and spatial coverage of the SSS response are all similar, but the MY2.5 shows slightly less freshening from precipitation. The precipitation effect on the salinity response is confined to a $\sim 5^{\circ}$ perpendicular cross section to Hurricane Gonzalo's track. The maximum SSS freshening response occurs directly under Hurricane Gonzalo, where precipitation forcing is strongest (Fig. 7).
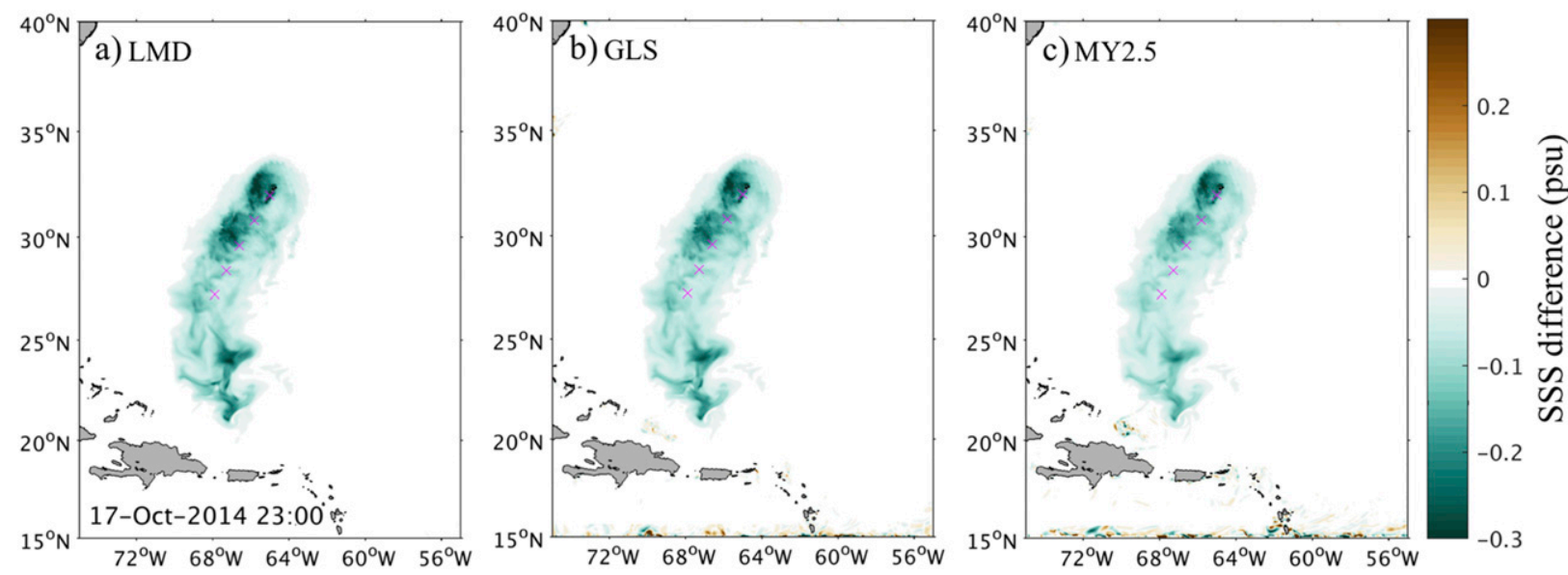

FIG. 7. ROMS model SSS response to precipitation forcing at 2300 UTC 17 Oct 2014 for (a) LMD, (b) GLS, and (c) MY2.5 vertical, turbulent mixing schemes, with the leading magenta " $\mathrm{x}$ " showing the best track location of Hurricane Gonzalo. Subsequent magenta $\mathrm{x}$ marks show previous best track locations every $6 \mathrm{~h}$ out to $24 \mathrm{~h}$ prior. 

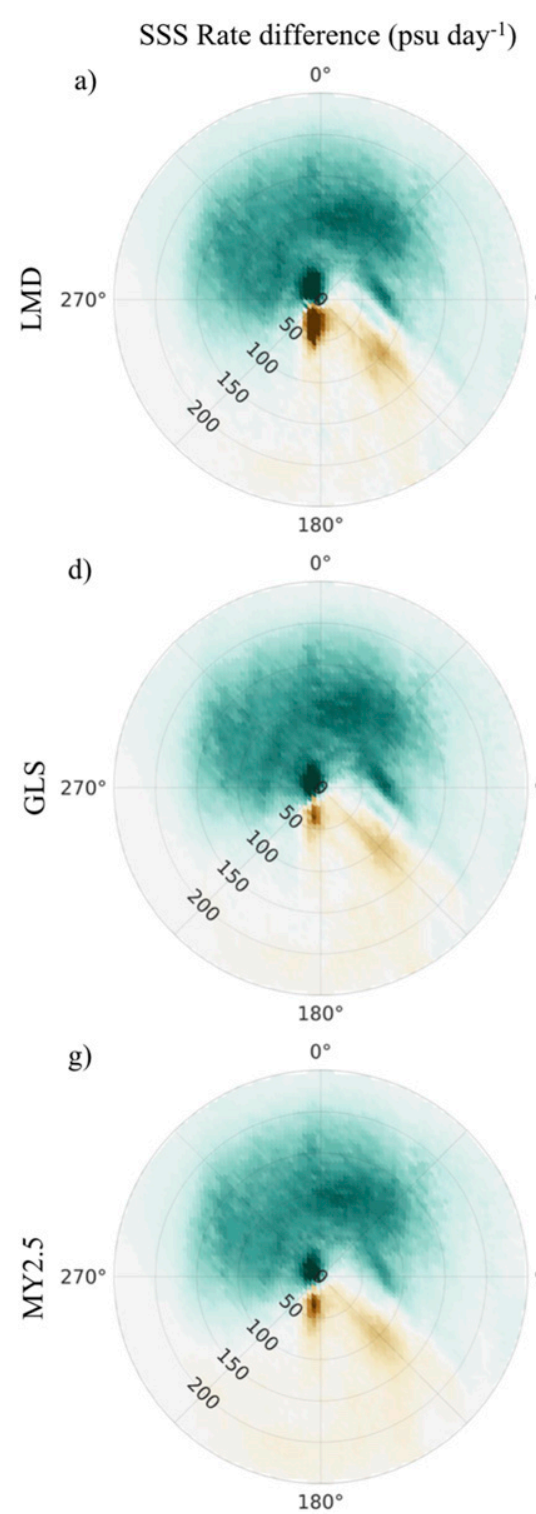

Hurricane Gonzalo Translation Direction

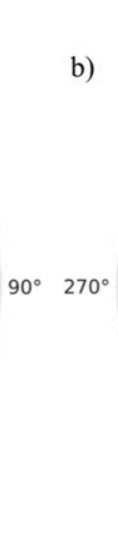

SSS TADV difference (psu day $\left.{ }^{-1}\right)$

b)

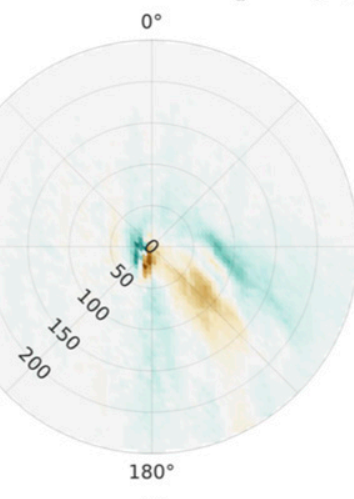

e)

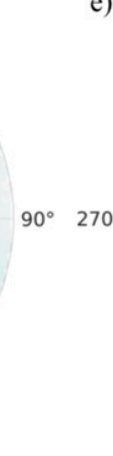

h)

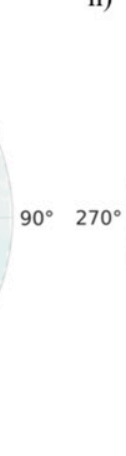

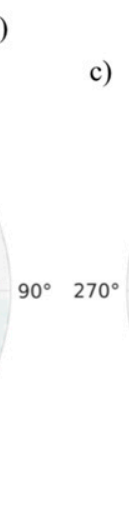

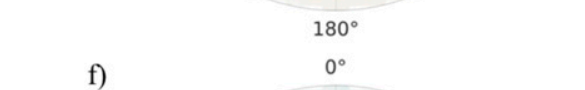

f)

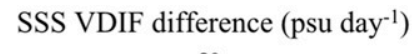

$90^{\circ}$

FIG. 8. Radial contour plots of differences in SSS tendency terms due to precipitation forcing (storm centered and rotated in direction of Hurricane Gonzalo translation direction). The three vertical, turbulent mixing schemes are (a)-(c) LMD, (d)-(f) GLS, and (g)-(i) MY2.5. Each panel encompasses the entire storm environment out to a radius of $250 \mathrm{~km}$ (gray contours every $50 \mathrm{~km}$ ). (left) The total SSS rate difference is the sum of (center) the total advection term and (right) the vertical diffusion term. Green (brown) shading indicates areas where the ROMS model runs with precipitation forcing have higher rates of freshening (salinification) than model runs without precipitation forcing.

The radial pattern of the salinity tendency terms is shown in Fig. 8, where negative values indicate net freshening. The strongest freshening rates occur within $50 \mathrm{~km}$ of the TC center where precipitation rates are the highest. Also, freshening extends out to $200 \mathrm{~km}$ ahead of the storm as southwesterly wind shear confined the higher precipitation rates to the front two quadrants (Fig. 8, left column). In these areas, where there is strong precipitation forcing, the vertical diffusion term acts to freshen the near-surface layer.
The total advection term plays a secondary role in determining the total SSS rate. The largest contribution from the SSS TADV term is mostly confined to the right side of the TC wake (from $90^{\circ}$ to $180^{\circ}$ in Figs. $8 \mathrm{~b}, \mathrm{e}, \mathrm{h}$ ). This region of the storm is characterized my strong upwelling and the vertical advection of saline water toward the surface. As a result, the spatial structure of the SSS TADV term is largely dictated by vertical advection. 

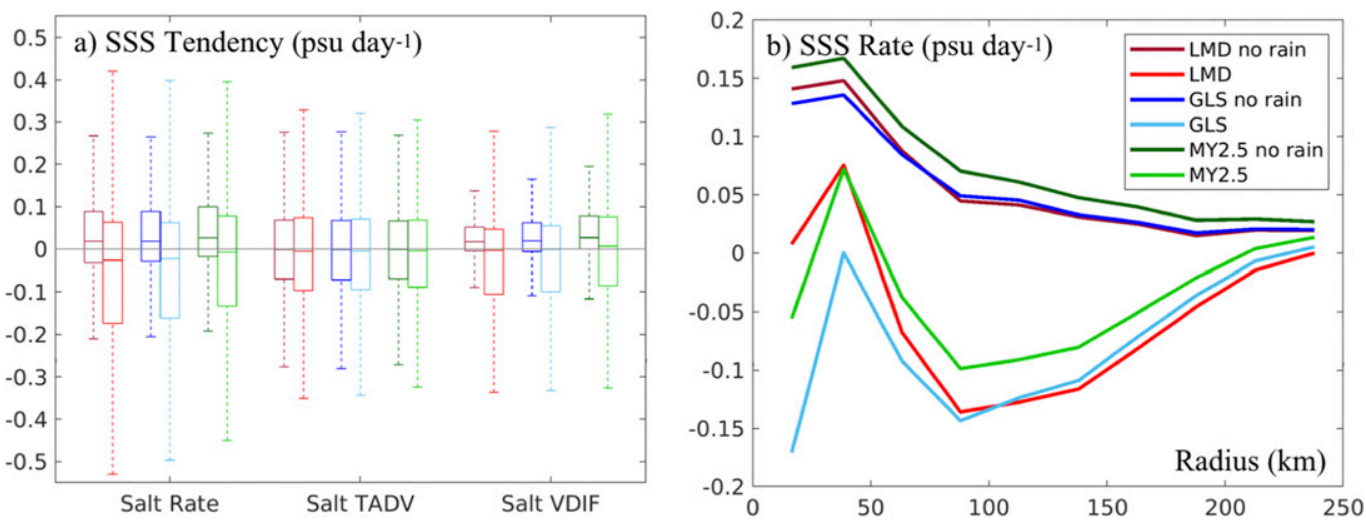

FIG. 9. (a) Boxplots of SSS tendency terms from all six ROMS model runs using LMD (red), GLS (blue), and MY2.5 (green) turbulent mixing schemes. Each boxplot encompasses the entire storm environment out to a radius of $250 \mathrm{~km}$. (b) The radial dependence of SSS rate is shown.

A strip of positive SSS tendency difference extends to the right of the storm track at a $135^{\circ}$ angle. As the TC passes and precipitation ends, continued vertical entrainment and turbulent mixing from strong inertial currents result in salinification. Increases in SSS are often observed in satellite analyses of hurricane cold wakes, but these remotely sensed observations are taken several days after TC passage (Reul et al. 2014). Since the upper ocean is fresher in the ROMS model runs with precipitation forcing, the salinification rates are stronger in the $\mathrm{TC}$ wake (from $90^{\circ}$ to $270^{\circ}$ ) due to the cessation of convective precipitation and the continued mixing of the water column.

The area-averaged SSS response to Hurricane Gonzalo is shown using boxplots of the ROMS tendency terms (Fig. 9). Generally, the boxplot results for SSS are consistent among the three turbulent closure schemes (Fig. 9a). The boxplots represent all grid points within a $250-\mathrm{km}$ radius of the TC center. The LMD and GLS schemes both have median values of total SSS tendency that are slightly below zero, indicating a propensity for freshening when precipitation forcing is applied. The LMD scheme has slightly broader values for the 25th and 75 th quartiles. For MY2.5, the median salting rate is near zero and there is less freshening compared to the other two closure schemes. All ROMS model runs without precipitation forcing have a positive median value in total SSS tendency that mirrors the vertical diffusion term (Fig. 9). This means, without a strong surface freshwater flux from precipitation, entrainment of subsurface water causes salinification within the mixed layer and at the surface.

The contribution from total advection is almost identical in median values and very close for the 25 th and 75 th quartiles. Therefore, there is not a substantial difference in the total advection in the salinity tendency among the three vertical mixing parameterizations. Since the experiments implement three difference vertical turbulent mixing parameterizations, the largest differences occur in the vertical diffusion term. Once again, MY2.5 has a vertical diffusion rate that results in more salinification near the surface. This is likely due to more vertical entrainment of high saline water from below the thermocline into the mixed layer.
The radially binned SSS rate shows that the strongest net freshening (negative SSS rate) occurs near $80-\mathrm{km}$ radius, when averaged across all ROMS model runs with precipitation forcing (Fig. 9b). In effect, the precipitation rates near $80 \mathrm{~km}$ are high, yet wind forcing and salinification due to entrainment are reduced compared to the eyewall region, which results in the strongest net freshening rates. Near the radius of maximum winds (between 25 and $50 \mathrm{~km}$ ), the enhanced turbulent mixing from TC wind forcing can overpower the precipitation forcing, resulting in salinification and a spike in SSS rate (Fig. 9b). Furthermore, inside of the $50 \mathrm{~km}$ radius, the SSS rates vary the most among the three turbulent mixing schemes. The LMD with precipitation has positive SSS rates for radii $<50 \mathrm{~km}$, while the GLS with precipitation has entirely negative SSS rates. Therefore, LMD has net salinification near the center of Hurricane Gonzalo, but GLS produces net freshening; the SSS rates are sensitive to the selection of the vertical, turbulent mixing schemes within ROMS. At larger radii $(>100 \mathrm{~km})$, the SSS freshening rate tapers off and approaches zero at a radius of $250 \mathrm{~km}$.

\section{c. Temperature response}

The SST response to TC precipitation can modify enthalpy fluxes into the TC and potentially effect TC boundary layer processes. From a modeling perspective, this is particularly true in fully coupled systems, where nonlinear processes in airsea interaction are important. Therefore, determining the SST sensitivity for different mixing parameterizations within the ROMS model provides insight into the air-sea interactions associated with TC precipitation. The absolute magnitude of ROMS SST differences can reach $\pm 0.3^{\circ} \mathrm{C}$, yet the spatially averaged SSTs within the inner-core region is less than a $0.1^{\circ} \mathrm{C}$ difference. An example of the SST difference field is contoured for the ROMS model output at 2300 UTC 17 October (Fig. 10). Overall, the SST response to precipitation forcing in the ROMS model is spatially heterogeneous, with areas of relative warming and cooling. The change in SSS due to precipitation is directly attributable to the surface freshwater flux, whereas the SST changes are governed by indirect physical processes that are modified by the precipitation forcing. 

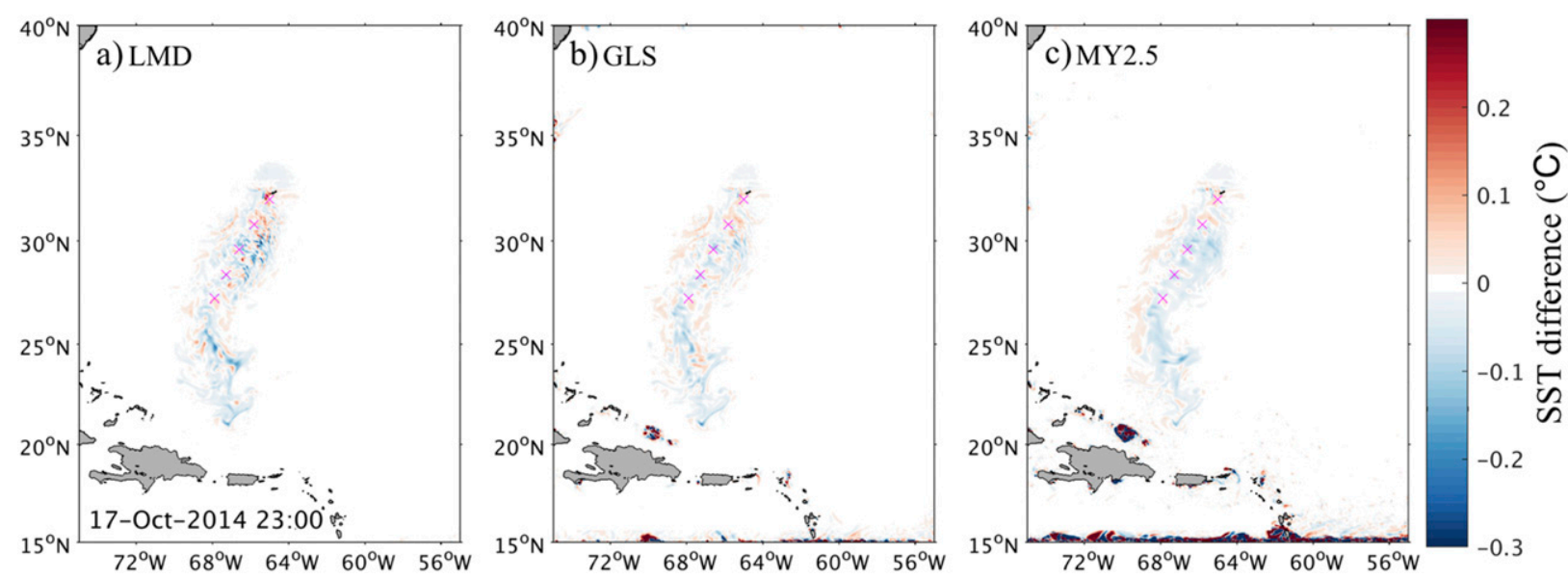

FIG. 10. ROMS model SST response to precipitation forcing at 2300 UTC 17 Oct 2014 for (a) LMD, (b) GLS, and (c) MY2.5 vertical, turbulent mixing schemes, with the leading magenta " $\mathrm{x}$ " showing the best track location of Hurricane Gonzalo. Subsequent magenta $\mathrm{x}$ marks show previous best track locations every $6 \mathrm{~h}$ out to $24 \mathrm{~h}$ prior.

The SST tendency differences have contributions from both the total advection term and the vertical diffusion term, but the spatial differences are mostly driven by the total advection term (Fig. 11). The banding structure in the SST total advection term is likely generated by instabilities along the right side of Hurricane Gonzalo's track, where current shear and upwelling are strong. The precipitation forcing in this region of the storm can cause differences in the internal wave field due to modifying upper-ocean stratification, which manifests as the wavelike structure in SST rate differences (Figs. 11a,d,g).

The LMD turbulent mixing parameterization has the strongest SST response to precipitation forcing. The largest differences in SST tendency are mostly to the right of Hurricane Gonzalo's track and can extend to a radius of $100-150 \mathrm{~km}$ (Fig. 11, left column). Furthermore, the vertical diffusion term shows positive SST tendencies of $0.1-0.2^{\circ} \mathrm{C}_{\text {day }}{ }^{-1}$ (light red shading) ahead of Hurricane Gonzalo's track out to $100 \mathrm{~km}$ radius which are collocated with high precipitation rates (Fig. 11c). This area of relatively warmer SSTs is likely due to the stabilizing effect of precipitation on the upper ocean. The stabilizing effect from precipitation is noticeably less in the GLS and MY2.5 runs (Figs. 11f,i). Since these changes in SST occur ahead of the TC track, they can have a direct impact on inner-core enthalpy fluxes.

There are regions with both positive and negative SST tendency differences. Therefore, the SST differences are not solely driven by increases in upper-ocean stratification that limit vertical entrainment. In areas where there is more SST cooling when precipitation forcing is applied, another mechanism must be responsible for this effect. The inclusion of rainfall temperature has a small impact on SST, contributing less than $10 \%$ to ocean heat loss (Jacob and Koblinsky 2007). One likely possibility is that precipitation forcing can affect the strength of near-surface ocean currents and modify ocean current shear, allowing instabilities to develop. In ROMS model runs with precipitation forcing, turbulent kinetic energy is increased in the upper $30-40 \mathrm{~m}$ of the ocean (not shown).
Enhanced shear-generated turbulent mixing is able to entrain cooler water into the mixed layer. This results in areas within the ROMS model domain that have more SST cooling (Fig. 11, blue shading), as turbulent mixing is more vigorous.

Boxplots of SST tendency show the SST cooling rates and individual budget terms for all six ROMS model configurations (Fig. 12). All of the parameterizations have net cooling rates, and MY2.5 has the strongest SST cooling response. The median value of the total advection term is near zero for all parameterizations and contributes little to the TC-induced cold wake. Therefore, SST tendency near Hurricane Gonzalo is largely determined by the vertical diffusion term, which includes entrainment mixing (Fig. 12). Differences in SST tendency due to precipitation forcing are small when considering all grid points within a $250 \mathrm{~km}$ radius of the TC center. SST cooling rates are between $-2^{\circ}$ and $-3^{\circ} \mathrm{C}_{\text {day }}{ }^{-1}$ near the TC center $\left(25 \mathrm{~km}\right.$ radius) and decrease quickly to between $-1^{\circ}$ and $-1.5^{\circ} \mathrm{C} \mathrm{day}^{-1}$ at a radius of $100 \mathrm{~km}$ (Fig. 12b).

Overall, vertical diffusion and entrainment are primarily responsible for SST cooling within the cold wake of Hurricane Gonzalo (Fig. 12a). The effect of precipitation forcing in the ROMS model has more influence on the total advection term in the SST tendency. The selection of a turbulent, vertical mixing scheme is more consequential to determining SST cooling rates under TC conditions than the inclusion of precipitation forcing. The GLS and LMD turbulent mixing schemes perform best when compared to Anna glider observations, while MY2.5 results in a stronger SST cooling response to Hurricane Gonzalo.

\section{d. Role of dynamic ocean coupling}

The surface freshwater flux to the ocean from precipitation associated with TC passage acts to increase the static stability of the upper ocean (Fig. 4, right column). This results in two competing, dynamically linked mechanisms that influence SST tendency. First, the increased static stability restricts the entrainment of cooler, subthermocline water into the mixed 


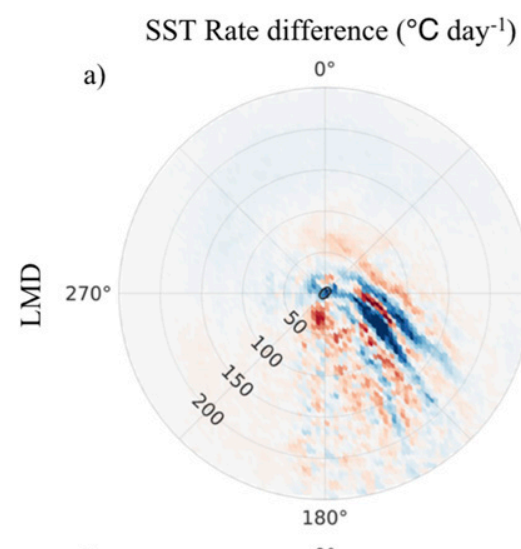

d)

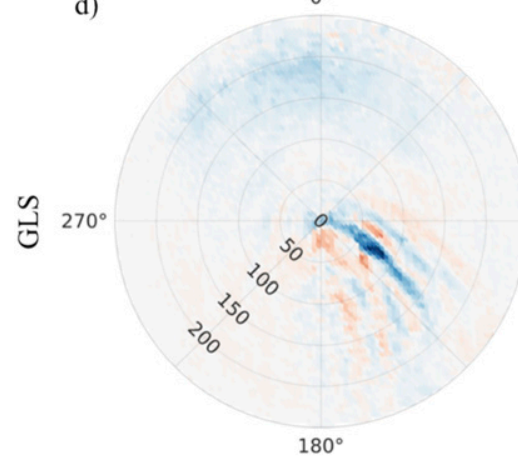

g)

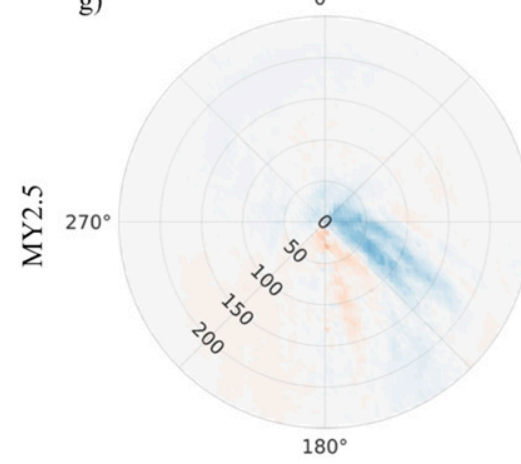

b)

$$
\text { SST TADV difference }\left({ }^{\circ} \mathrm{C} \text { day }{ }^{-1}\right)
$$

$90^{\circ} 270^{\circ}$

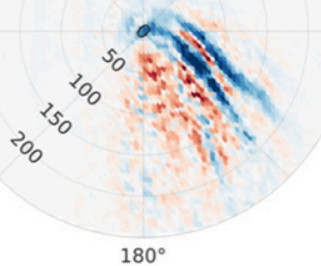

e)

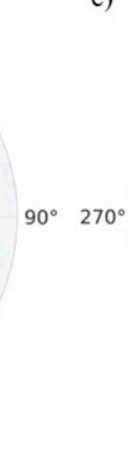

h)

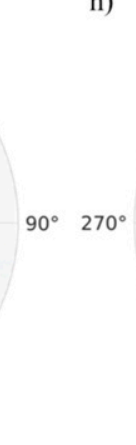

$0^{\circ}$

$90^{\circ}$

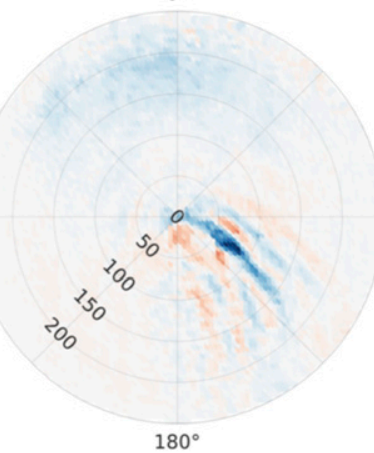

$0^{\circ}$ c)

\section{SST VDIF difference $\left({ }^{\circ} \mathrm{C}\right.$ day $\left.^{-1}\right)$}

$0^{\circ}$

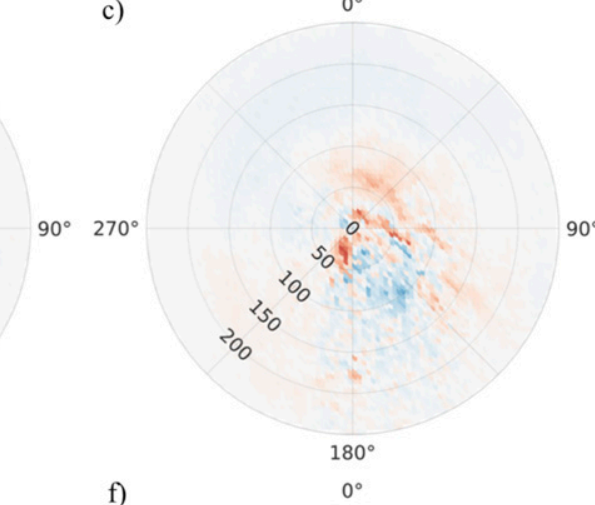

$90^{\circ} \quad 270^{\circ}$

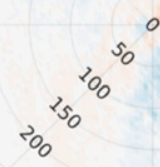

i)

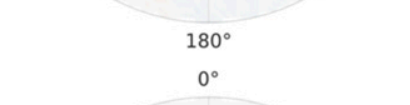

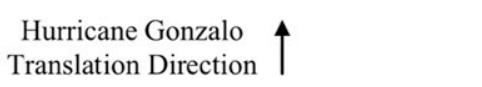

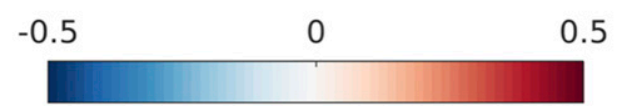

FIG. 11. Radial contour plots of differences in SST tendency terms due to precipitation forcing (storm centered and rotated in direction of Hurricane Gonzalo translation direction). The three vertical, turbulent mixing schemes are (a)-(c) LMD, (d)-(f) GLS, and (g)-(i) MY2.5. Each panel encompasses the entire storm environment out to a radius of $250 \mathrm{~km}$ (gray contours every $50 \mathrm{~km}$ ). (left) The total SST rate difference is the sum of (center) the total advection term and (right) the vertical diffusion term. Red (blue) shading indicates areas where the ROMS model runs with precipitation forcing have higher rates of warming (cooling) than model runs without precipitation forcing.

layer. Then, the magnitude of SST cooling under the TC and within the cold wake is reduced. This feedback can facilitate a more favorable thermodynamic environment for the TC since enthalpy fluxes into the storm are maintained. The salinitydriven stability mechanism has been proposed in previous literature as a beneficial air-sea interaction for TC intensification (Jacob and Koblinsky 2007; Wang et al. 2011; Balaguru et al. 2012; Neetu et al. 2012; Jourdain et al. 2013; Rudzin et al. 2017;
Steffen and Bourassa 2018; Rudzin et al. 2019; Hlywiak and Nolan 2019, and others).

However, another consequence to precipitation-enhanced stratification within the upper ocean is how the ocean currents respond. The kinetic energy of upper-ocean currents, from 0to $30-\mathrm{m}$ depth, is higher for ROMS model simulations with precipitation forcing than model runs without precipitation forcing. An increase in current shear occurs because wind 

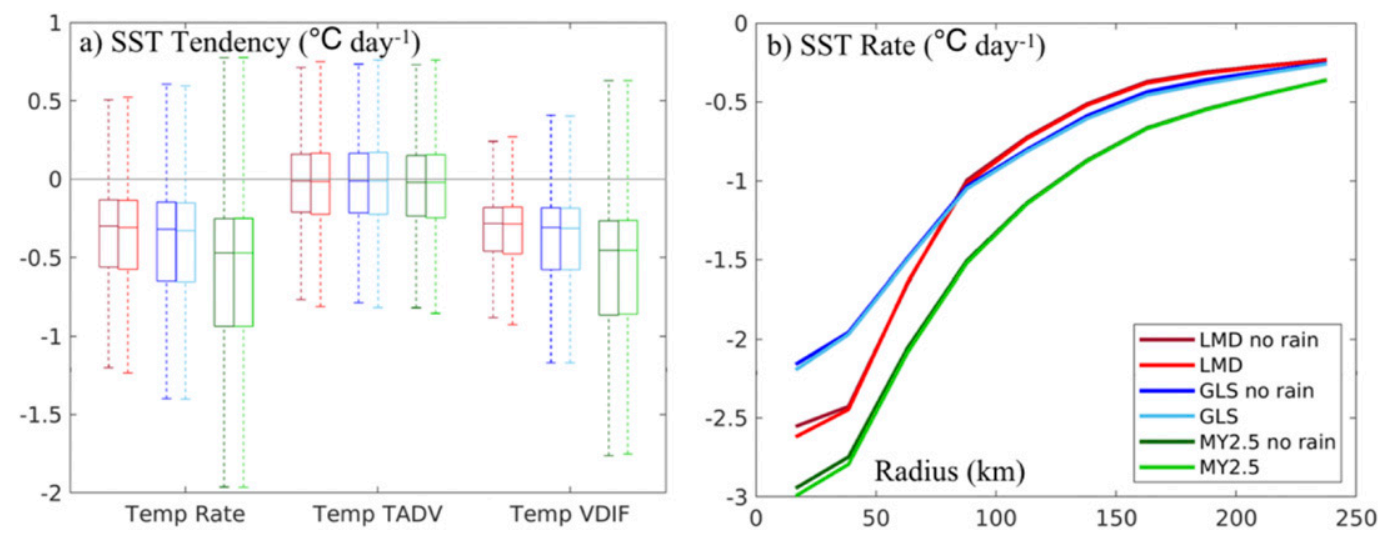

FIG. 12. (a) Boxplots of SST tendency terms from all six ROMS model runs using LMD (red), GLS (blue), and MY2.5 (green) turbulent mixing schemes. Each boxplot encompasses the entire storm environment out to a radius of $250 \mathrm{~km}$. (b) The radial dependence of SST rate is shown.

stress imparted to the ocean surface is retained in the upper layers of the ocean (Fig. 13). Using ROMS model grid points that experience SSS freshening of 0.1 psu or more, upper-ocean stratification and current shear are highly correlated, with an $R$ value of 0.77 . Therefore, precipitation also enhances upperocean current shear which can result in more turbulent mixing if criticality is reached. The modification of near-surface currents by TC precipitation acts to counteract the stabilizing effect of upper-ocean freshening, a finding that has not been addressed in previous studies.

\section{Discussion}

The intent of the ROMS model hindcasts is to improve the understanding of coupled air-sea interactions related to TC precipitation. By forcing high-resolution models with researchquality observations, the mechanisms responsible for barrier layer development in Hurricane Gonzalo are explored. The two main research questions addressed in this study are as follows: First, how strong is the surface freshwater flux during TC forcing and what are the prominent terms in the nearsurface salinity budget? Second, does TC precipitation effect upper-ocean stratification or other physical processes that can modify the SST cooling response?

In answer to the first question, ROMS model output and Anna glider measurements show that the SSS response results in net freshening of $0.3 \mathrm{psu}$ within the forced region of the TC. Freshwater anomalies extend into the mixed layer and can penetrate past the thermocline depth under strong turbulent mixing from TC wind forcing. In regions with high precipitation rates, vertical diffusion and turbulent mixing are the primary processes for distributing the surface freshwater flux to deeper layers. A notable result is the near-surface salinity response to precipitation forcing is sensitive to the selection of a turbulence closure scheme. For example, using the same atmospheric forcing across all ROMS model runs, the MY2.5 scheme produced more turbulent mixing, which resulted in less near-surface freshening compared to the LMD and GLS schemes. How the different turbulent mixing schemes distribute the surface freshwater forcing throughout the mixed layer has a direct influence on upper-ocean currents, which can modify the SST cooling response under Hurricane Gonzalo.

To address the second question, there are areas near Hurricane Gonzalo with SST changes as large as $\pm 0.3^{\circ} \mathrm{C}$ that can modify atmospheric boundary layer processes and influence the thermodynamic forcing to the TC. While a large source of SST variability within ROMS can be attributed to the different vertical mixing schemes, precipitation forcing plays an active role in modifying the SST response to Hurricane Gonzalo. Overall, precipitation forcing results in upper-ocean freshening, which acts to increase ocean stratification and barrier layer strength. If a salinity-driven increase in stratification was

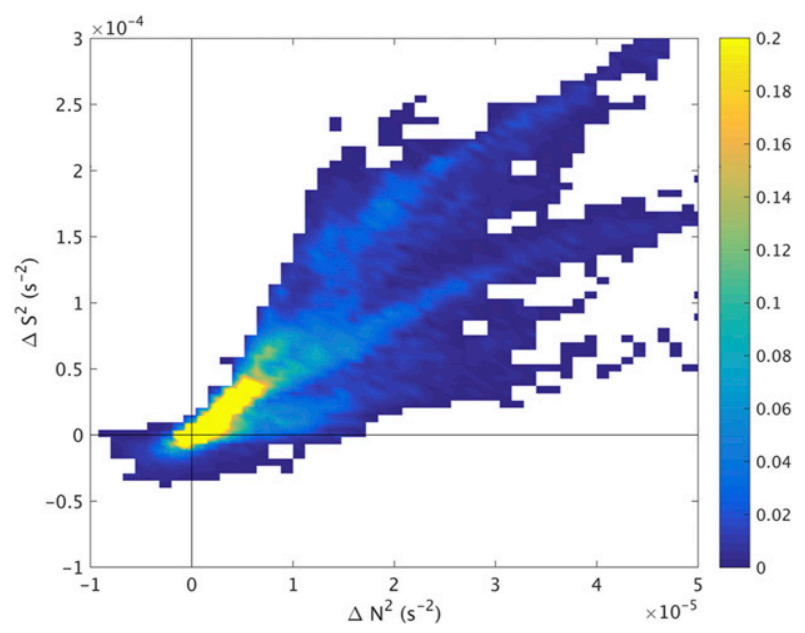

FIG. 13. Normalized density plot (shading) of the relationship between changes in squared Brunt-Väisälä buoyancy frequency $\left(\Delta N^{2}\right)$ and ocean current shear $\left(\Delta S^{2}\right)$ within the upper ocean (vertical average from 0 - to $30-\mathrm{m}$ depth) due to precipitation forcing. The selected data points have SSS freshening of $0.1 \mathrm{psu}$ or more, isolating the areas with strong precipitation forcing during Hurricane Gonzalo. The $\Delta N^{2}$ and $\Delta S^{2}$ are differences between ROMS model runs (GLS turbulent mixing scheme) with precipitation forcing minus no-precipitation forcing. 
the only mechanism at play, then the ROMS model runs with precipitation forcing should have warmer SSTs near Hurricane Gonzalo, since entrainment mixing should be reduced. However, the SST differences (precipitation minus no-precipitation forcing) are spatially heterogeneous, with areas of both relative warming and cooling. The dynamic coupling between precipitation-induced changes in $N^{2}$ and $S^{2}$ produces increased current shear within the upper ocean. Therefore, there are competing effects from precipitation forcing in the ROMS models runs that affect SST: an increase in static stability resists turbulent mixing, yet ocean current shear acts to erode the stratification. During the forced stage of Hurricane Gonzalo, nonlinear interactions between upper-ocean stability and current shear result in the spatial heterogeneity of SST differences. This is especially true to the right of the TC track where vertical processes, like upwelling, are prevalent. Observations from the Anna glider and ROMS model experiments support that precipitation forcing has an appreciable impact on the upper-ocean responses of salinity, temperature, and currents during Hurricane Gonzalo.

Acknowledgments. This work was supported by the National Aeronautics and Space Administration (NASA; Grant NNX15AD45G) and the National Oceanic and Atmospheric Administration (NOAA; Grant NA11OAR4320199). Slocum glider data obtained during Hurricane Gonzalo were generously provided by Ruth Curry and Mark Guishard from the Bermuda Institute of Ocean Sciences (BIOS). Surface wind observations were obtained from the Risk Management Solutions (RMS) $\mathrm{H}^{*}$ Wind product, with support from Dr. Mark Powell and Chana Keating. The authors would also like to thank Dr. John Warner (USGS, Woods Hole, MA) for advice on the COAWST model setup.

\section{REFERENCES}

Androulidakis, Y., V. Kourafalou, G. Halliwell, M. Le Hénaff, H. Kang, M. Mehari, and R. Atlas, 2016: Hurricane interaction with the upper ocean in the Amazon-Orinoco plume region. Ocean Dyn., 66, 1559-1588, https://doi.org/10.1007/s10236016-0997-0.

Balaguru, K., P. Chang, R. Saravanan, L. R. Leung, Z. Xu, M. Li, and J.-S. Hsieh, 2012: Ocean barrier layers' effect on tropical cyclone intensification. Proc. Natl. Acad. Sci. USA, 109, 14343-14 347, https://doi.org/10.1073/pnas.1201364109.

Brown, D. P., 2015: Hurricane Gonzalo. National Hurricane Center Tropical Cyclone Rep., 30 pp., https://www.nhc.noaa.gov/data/ tcr/AL082014_Gonzalo.pdf.

Chassignet, E. P., H. E. Hurlburt, O. M. Smedstad, G. R. Halliwell, P. J. Hogan, A. J. Wallcraft, R. Baraille, and R. Bleck, 2007: The HYCOM (HYbrid Coordinate Ocean Model) data assimilative system. J. Mar. Syst., 65, 60-83, https://doi.org/ 10.1016/j.jmarsys.2005.09.016.

Cione, J. J., and E. W. Uhlhorn, 2003: Sea surface temperature variability in hurricanes: Implications with respect to intensity change. Mon. Wea. Rev., 131, 1783-1796, https://doi.org/ $10.1175 / / 2562.1$.

Cummings, J. A., 2005: Operational multivariate ocean data assimilation. Quart. J. Roy. Meteor. Soc., 131, 3583-3604, https:// doi.org/10.1256/qj.05.105.
Curry, R., and M. Guishard, 2016: Glider observations of upper ocean temperature and dynamics during three hurricane passages through the western Atlantic. 32nd Conf. on Hurricanes and Tropical Meteorology, San Juan, PR, Amer. Meteor. Soc., 3B.3, https://ams.confex.com/ams/32Hurr/ webprogram/Paper293057.html.

Doelling, D., 2017: CERES Level 3 SYN1deg-3Hour Terra +Aqua HDF4 file - Edition 4A. NASA Earthdata, accessed 9 August 2018, https://doi.org/10.5067/TERRA+AQUA/CERES/ SYN1DEG-3HOUR_L3.004A.

Domingues, R., and Coauthors, 2015: Upper ocean response to Hurricane Gonzalo (2014): Salinity effects revealed by targeted and sustained underwater glider observations. Geophys. Res. Lett., 42, 7131-7138, https://doi.org/10.1002/ 2015 GL065378.

Elsberry, R. L., T. S. Fraim, and R. N. Trapnell, 1976: A mixed layer model of the oceanic thermal response to hurricanes. J. Geophys. Res., 81, 1153-1162, https://doi.org/10.1029/ JC081i006p01153.

Emanuel, K. A., 1995: Sensitivity of tropical cyclones to surface exchange coefficients and a revised steady-state model incorporating eye dynamics. J. Atmos. Sci., 52, 3969-3976, https://doi.org/ 10.1175/1520-0469(1995)052<3969:SOTCTS >2.0.CO;2.

Fisher, E. L., 1958: Hurricanes and the sea-surface temperature field. J. Meteor., 15, 328-333, https://doi.org/10.1175/15200469(1958)015<0328:HATSST $>2.0$.CO;2.

Grodsky, S. A., and Coauthors, 2012: Haline hurricane wake in the Amazon/Orinoco plume: AQUARIUS/SACD and SMOS observations. Geophys. Res. Lett., 39, L20603, https://doi.org/ 10.1029/2012GL053335.

Harper, B. A., J. D. Kepert, and J. D. Ginger, 2010: Guidelines for converting between various wind averaging periods in tropical cyclone conditions. World Meteorological Organization Rep., 54 pp., https://www.wmo.int/pages/prog/www/tcp/documents/ WMO_TD_1555_en.pdf.

Hernandez, O., J. Jouanno, and F. Durand, 2016: Do the Amazon and Orinoco freshwater plumes really matter for hurricaneinduced ocean surface cooling? J. Geophys. Res. Oceans, 121, 2119-2141, https://doi.org/10.1002/2015JC011021.

Hlywiak, J., and D. S. Nolan, 2019: The influence of oceanic barrier layers on tropical cyclone intensity as determined through idealized, coupled numerical simulations. J. Phys. Oceanogr., 49, 1723-1745, https://doi.org/10.1175/JPO-D-18-0267.1.

Huffman, G. J., and Coauthors, 2018: NASA Global Precipitation Measurement (GPM) Integrated Multi-satellitE Retrievals for GPM (I-MERG). Algorithm Theoretical Basis Doc., version 5.2, 36 pp., https://pmm.nasa.gov/sites/default/files/ document_files/IMERG_ATBD_V5.2_0.pdf.

Jacob, S. D., and C. J. Koblinsky, 2007: Effects of precipitation on the upper-ocean response to a hurricane. Mon. Wea. Rev., 135, 2207-2225, https://doi.org/10.1175/MWR3366.1.

Jourdain, N. C., M. Lengaigne, J. Vialard, G. Madec, C. E. Menkes, E. M. Vincent, S. Jullien, and B. Barnier, 2013: Observationbased estimates of surface cooling inhibition by heavy rainfall under tropical cyclones. J. Phys. Oceanogr., 43, 205-221, https://doi.org/10.1175/JPO-D-12-085.1.

Large, W. G., J. C. McWilliams, and S. C. Doney, 1994: Oceanic vertical mixing: A review and a model with a nonlocal boundary layer parameterization. Rev. Geophys., 32, 363, https://doi.org/10.1029/94RG01872.

Leipper, D. F., 1967: Observed ocean conditions and Hurricane Hilda, 1964. J. Atmos. Sci., 24, 182-186, https://doi.org/10.1175/ 1520-0469(1967)024<0182:OOCAHH>2.0.CO;2. 
Liu, Z., J. Xu, B. Zhu, C. Sun, and L. Zhang, 2007: The upper ocean response to tropical cyclones in the northwestern Pacific analyzed with Argo data. Chin. J. Oceanology Limnol., 25, 123-131, https://doi.org/10.1007/s00343-0070123-8.

Mellor, G. L., and T. Yamada, 1982: Development of a turbulence closure model for geophysical fluid problems. Rev. Geophys., 20, 851, https://doi.org/10.1029/RG020i004p00851.

Neetu, S., M. Lengaigne, E. M. Vincent, J. Vialard, G. Madec, G. Samson, M. R. Ramesh Kumar, and F. Durand, 2012: Influence of upper-ocean stratification on tropical cycloneinduced surface cooling in the Bay of Bengal. J. Geophys. Res., 117, C12020, https://doi.org/10.1029/2012JC008433.

NOAA/NCEP, 2000: NCEP FNL Operational Model Global Tropospheric Analyses, continuing from July 1999 (updated daily). National Center for Atmospheric Research Computa tional and Information Systems Laboratory Research Data Archive, accessed 25 September 2018, https://doi.org/10.5065/ D6M043C6.

Park, J. J., Y.-O. Kwon, and J. F. Price, 2011: Argo array observation of ocean heat content changes induced by tropical cyclones in the north Pacific. J. Geophys. Res., 116, C12025, https://doi.org/10.1029/2011JC007165.

Powell, M. D., S. H. Houston, L. R. Amat, and N. MorisseauLeroy, 1998: The HRD real-time hurricane wind analysis system. J. Wind Eng. Ind. Aerodyn., 77-78, 53-64, https:// doi.org/10.1016/S0167-6105(98)00131-7.

—_ and Coauthors, 2010: Reconstruction of Hurricane Katrina's wind fields for storm surge and wave hindcasting. Ocean Eng., 37, 26-36, https://doi.org/10.1016/j.oceaneng.2009.08.014.

Price, J. F., 1981: Upper ocean response to a hurricane. J. Phys. Oceanogr., 11, 153-175, https://doi.org/10.1175/1520-0485(1981) 011<0153:UORTAH > 2.0.CO;2.

Reul, N., Y. Quilfen, B. Chapron, S. Fournier, V. Kudryavtsev, and R. Sabia, 2014: Multisensor observations of the Amazon-Orinoco river plume interactions with hurricanes. J. Geophys. Res. Oceans, 119, 8271-8295, https:// doi.org/10.1002/2014JC010107.

Rudzin, J. E., L. K. Shay, B. Jaimes, and J. K. Brewster, 2017: Upper ocean observations in eastern Caribbean Sea reveal barrier layer within a warm core eddy. J. Geophys. Res. Oceans, $\mathbf{1 2 2}$, 1057-1071, https://doi.org/10.1002/2016JC012339.

, and B. Jaimes de la Cruz, 2019: The impact of the Amazon-Orinoco river plume on enthalpy flux and air-sea interaction within Caribbean Sea tropical cyclones. Mon. Wea. Rev., 147, 931-950, https://doi.org/10.1175/MWR-D18-0295.1.
Shay, L. K., G. J. Goni, and P. G. Black, 2000: Effects of a warm oceanic feature on Hurricane Opal. Mon. Wea. Rev., 128, 1366-1383, https://doi.org/10.1175/1520-0493(2000)128<1366: EOAWOF $>2.0 . \mathrm{CO} ; 2$.

Shchepetkin, A. F., and J. C. McWilliams, 2005: The Regional Oceanic Modeling System (ROMS): A split-explicit, freesurface, topography-following-coordinate oceanic model. Ocean Modell., 9, 347-404, https://doi.org/10.1016/j.ocemod.2004.08.002.

Steffen, J., and M. Bourassa, 2018: Barrier layer development local to tropical cyclones based on Argo float observations. J. Phys. Oceanogr., 48, 1951-1968, https://doi.org/10.1175/JPO-D-170262.1.

Umlauf, L., and H. Burchard, 2003: A generic length-scale equation for geophysical turbulence models. J. Mar. Res., 61, 235265, https://doi.org/10.1357/002224003322005087.

Vissa, N. K., A. N. V. Satyanarayana, and B. P. Kumar, 2013: Response of upper ocean and impact of barrier layer on Sidr cyclone induced sea surface cooling. Ocean Sci. J., 48, 279-288, https://doi.org/10.1007/s12601-013-0026-x.

Wang, G., L. Wu, N. C. Johnson, and Z. Ling, 2016: Observed three-dimensional structure of ocean cooling induced by Pacific tropical cyclones. Geophys. Res. Lett., 43, 7632-7638, https://doi.org/10.1002/2016GL069605.

Wang, X., G. Han, Y. Qi, and W. Li, 2011: Impact of barrier layer on typhoon-induced sea surface cooling. Dyn. Atmos. Oceans, 52, 367-385, https://doi.org/10.1016/j.dynatmoce.2011.05.002.

Warner, J. C., C. R. Sherwood, H. G. Arango, and R. P. Signell, 2005: Performance of four turbulence closure models implemented using a generic length scale method. Ocean Modell., 8, 81-113, https://doi.org/10.1016/j.ocemod.2003.12.003.

— B. B. Armstrong, R. He, and J. B. Zambon, 2010: Development of a Coupled Ocean-Atmosphere-Wave-Sediment Transport (COAWST) Modeling System. Ocean Modell., 35, 230-244, https://doi.org/10.1016/j.ocemod.2010.07.010.

Wielicki, B. A., B. R. Barkstrom, E. F. Harrison, R. B. Lee, G. L. Smith, and J. E. Cooper, 1996: Clouds and the Earth's Radiant Energy System (CERES): An Earth observing system experiment. Bull. Amer. Meteor. Soc., 77, 853-868, https://doi.org/ 10.1175/1520-0477(1996)077<0853:CATERE >2.0.CO;2.

$\mathrm{Xu}, \mathrm{J}$., and Y. Wang, 2010: Sensitivity of tropical cyclone innercore size and intensity to the radial distribution of surface entropy flux. J. Atmos. Sci., 67, 1831-1852, https://doi.org/ 10.1175/2010JAS3387.1.

Yan, Y., L. Li, and C. Wang, 2017: The effects of oceanic barrier layer on the upper ocean response to tropical cyclones. J. Geophys. Res. Oceans, 122, 4829-4844, https://doi.org/ 10.1002/2017JC012694. 